Earth Interactions - Volume 23 (2019) • Paper No. 5 • Page 1

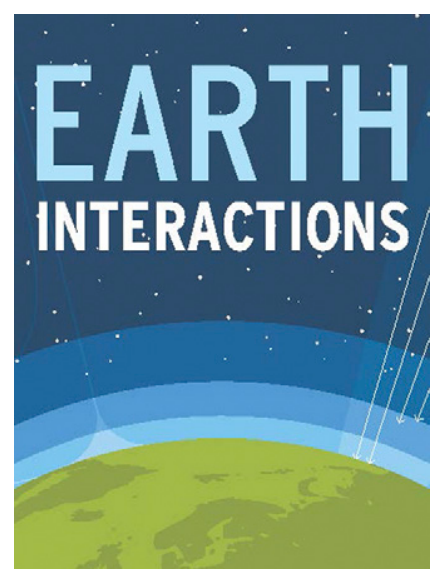

(C) 2019 American Meteorological Society. For information regarding reuse of this content and general copyright information, consult the AMS Copyright Policy (www.ametsoc.org/PUBSReuseLicenses).

\title{
A Spatial Pattern Analysis of Land Surface Roughness Heterogeneity and its Relationship to the Initiation of Weak Tornadoes
}

\section{Amanda Markert, ${ }^{a}$ Robert Griffin, and Kevin Knupp}

University of Alabama in Huntsville, Huntsville, Alabama

\section{Andrew Molthan}

NASA Marshall Space Flight Center, Huntsville, Alabama

\section{Tim Coleman}

University of Alabama in Huntsville, Huntsville, Alabama

Received 22 May 2018; in final form 30 January 2019

\begin{abstract}
North Alabama is among the most tornado-prone regions in the United States and is composed of more spatially variable terrain and land cover than the frequently studied North American Great Plains region. Because of the high tornado frequency observed across north Alabama, there is a need to understand how land surface roughness heterogeneity influences tornadogenesis, particularly for weak-intensity tornadoes. This study investigates whether horizontal gradients in land surface roughness exist surrounding locations of tornadogenesis for weak (EF0-EF1) tornadoes. The existence of the horizontal

\footnotetext{
a Corresponding author: Amanda Markert, amw0039@uah.edu
} 
Earth Interactions - Volume 23 (2019) • Paper No. 5 • Page 2

gradients could lead to the generation of positive values of the vertical components of the 3D vorticity vector near the surface that may aid in the tornadogenesis process. In this study, surface roughness was estimated using parameterizations from the Noah land surface model with inputs from MODIS 500-m and Landsat 30-m data. Spatial variations in the parameterized roughness lengths were assessed using GIS-based grid and quadrant pattern analyses to quantify observed variation of land surface features surrounding tornadogenesis locations across spatial scales. This analysis determined that statistically significant horizontal gradients in surface roughness exist surrounding tornadogenesis locations.

KEYWORDS: Atmosphere-land interaction; Boundary layer; Geographic information systems (GIS); Land surface; Tornadoes; Tornadogenesis

\section{Introduction}

The United States leads the world in tornado occurrence, averaging around 1000 events recorded annually (NCEI 2016). Within the United States, some locations experience a disproportionately higher frequency of tornadoes, which poses a higher risk to inhabiting citizens who suffer from the economic and societal impacts. North Alabama is one of these locations found by Coleman and Dixon (2014) to be among the most at risk areas for significant tornadoes [enhanced Fujita scale 2 (EF2) and greater] in the country. In addition, north Alabama has suffered from the most prolific tornado outbreaks in recorded history including the 3 April 1974 and 25-27 April 2011 outbreaks (Knupp 2014).

Within north Alabama, the NOAA National Weather Service Weather Forecast Office (WFO) operational forecasters, broadcast meteorologists, private industry weather companies, and the public have observed spatial patterns in tornado distribution and frequency. A spatial density map generated using the NOAA Severe Weather GIS (SVRGIS) dataset EF0-EF5 tornado tracks observed within the University of Alabama in Huntsville (UAH) operated Advanced Radar for Meteorological and Operational Research (ARMOR) coverage area is shown in Figure 1 (NOAA 2015). For tornado events captured prior to the 1973 enactment of the Fujita scale, tornado intensity was determined according to a property loss threshold if monetary damage information was available (NOAA 2015). In 2007 when the EF scale began being used, the Fujita scale rankings were converted to the EF scale and catalogued within the dataset. The generated map indicates two areas with high densities, or high frequencies of tornadoes for a given area. One area is located over north-central Alabama into southern Tennessee, while a second is located over the Cumberland Plateau extending into Marshall, Jackson, and DeKalb Counties. Compared to the frequently studied Great Plains region, north Alabama has greater variability in topography and vegetation, posing questions on how the lowest several hundred meters of the atmosphere, that is, the surface layer to lower boundary layer are influenced by horizontal gradients in the land surface roughness and how the tornadogenesis process may be affected.

Tornadogenesis occurs within both supercell storms and quasi-linear convective systems (QLCS). Since a significant majority of high-intensity (EF2-EF5) tornadoes occurs within supercell storms, previous research has focused on the development of low-level vertical vorticity within supercell storms via horizontal gradients in buoyancy at low levels (Davies-Jones 2015; Markowski et al. 2018, and references cited therein). The development of mesovortices within QLCSs has also been related 


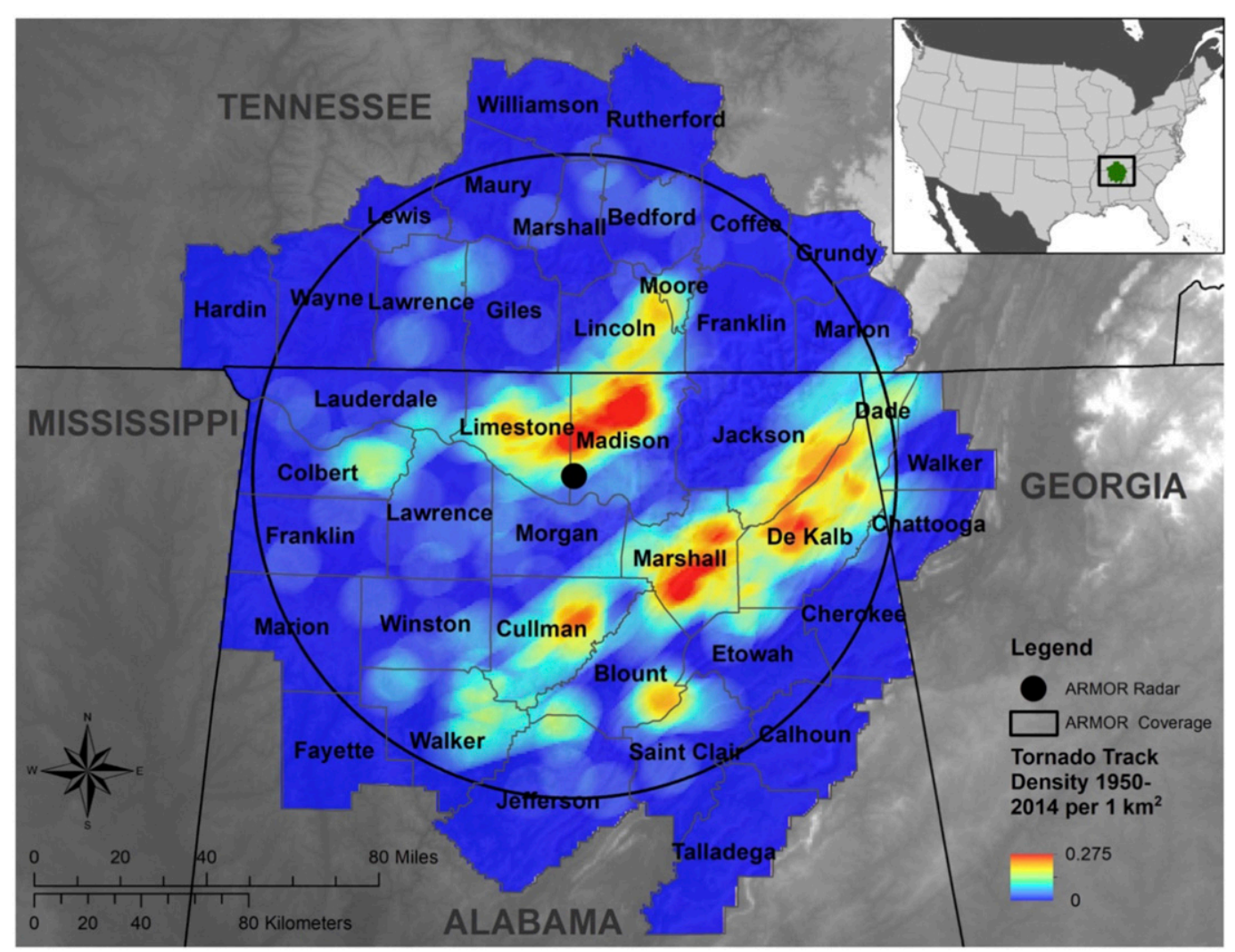

Figure 1. Tornado-track density for all EFO-EF5 tornadoes that occurred across counties intersecting the ARMOR coverage area from 1950 to 2014. This map reveals two areas with high frequencies of tornado occurrences for a given area. One area is located over north-central Alabama into southern Tennessee. The second area is located in the Cumberland Plateau extending into Marshall, Jackson, and DeKalb Counties.

to the development of horizontal gradients in buoyancy (Atkins and Laurent 2009), development of rotors by surface friction (Schenkman et al. 2012), and horizontal shearing instability (Conrad and Knupp 2019). This study focuses on weak-intensity tornadoes (EF0-EF1) since they are more numerous and are potentially influenced by horizontal variations in land surface roughness, according to the primary hypothesis defined in the following. For both storm types, Markowski et al. (2018, p. 3623) has stated, "A better understanding is needed of what can trigger a storm in a favorable environment to suddenly make a tornado at a particular stage in its evolution."

Decades of land surface remote sensing, tornado event observations, and geospatial tools enable variations in land surface features and tornado events to be assessed geostatistically as a first step toward characterizing how they affect tornadogenesis. This study integrates land surface remote sensing parameters, tornadogenesis locations, geospatial analysis, and the vertical component of the 3D vorticity equation to propose a novel, interdisciplinary approach to studying spatial relationships between land surface roughness variation and tornadogenesis. The goal of this study was to 
Earth Interactions - Volume 23 (2019) • Paper No. 5 • Page 4

determine whether horizontal gradients in land surface roughness exist in the surrounding locations of tornadogenesis for weak (EF0-EF1) tornadoes. The existence of the horizontal gradients could lead to the generation of positive values of the vertical components of the 3D vorticity vector near the surface in the lowest several hundred meters of the atmosphere (surface layer to lower boundary layer) that may aid in the tornadogenesis process. We accomplish this goal by 1) parameterizing surface roughness using satellite remote sensing and land surface model schemes, 2) running a spatial pattern analysis to assess spatial roughness variation surrounding locations of tornadogenesis, 3) conducting a quadrant pattern analysis to statistically identify significant relationships between horizontal roughness gradients and tornadogenesis locations, and 4) conduct this study using 30- and 500-m land surface data to assess if the same patterns are observed at varying spatial scales. The developed methods present a comprehensive and novel GIS-based approach for quantifying variations in surface friction using land surface roughness parameterization schemes and spatially assessing its variation in north Alabama surrounding EF0-EF1 tornadogenesis locations.

\section{Background}

\subsection{Defining roughness length}

Land surface roughness is a measure of the dynamic interaction between the land surface and the wind profile near the surface used to quantify the reduction in wind speed by drag force and friction (Raupach 1994; Holton 2004). The roughness of the land surface depends on the vertical deviation from an ideal, homogeneous surface at neutral stability created by variable land cover and topography. Within the logarithmic wind profile equation, the roughness length term $z_{0}$ is quantified in units of length. Equation (1) shows the terms of the logarithmic wind profile equation rearranged to equate to $z_{0}(\mathrm{~m})$ :

$$
z_{0}=z \exp \left[-k u(z) u_{*}^{-1}\right]
$$

where $u(z)$ is the mean flow velocity profile $\left(\mathrm{m} \mathrm{s}^{-1}\right)$ over a surface, $u_{*}$ is the friction velocity $\left(\mathrm{m} \mathrm{s}^{-1}\right), k$ is the von Kármán constant $(0.4)$, and $z$ is the height above ground level $(\mathrm{m})$. The friction velocity $u_{*}$ shown in Equation (2) accounts for shearing stress near the ground:

$$
u_{*}=\sqrt{\frac{\tau}{\rho}},
$$

where $\tau$ is the shear stress $\left(\mathrm{kg} \mathrm{m}^{-1} \mathrm{~s}^{-2}\right)$, and $\rho$ is the density of a fluid $\left(\mathrm{kg} \mathrm{m}^{-3}\right)$. The larger the value of $z_{0}$, the greater amount of frictional drag exerted on air moving over the land surface, thus corresponding to reduced wind shear.

\subsection{Vorticity and tornadogenesis}

Between areas with different magnitudes of $z_{0}$ there exist horizontal gradients in low-level flow moving over these surfaces that are most notable between areas of high (forest) and low (water, smooth grass surfaces) $z_{0}$. Coleman and Knupp (2009) 


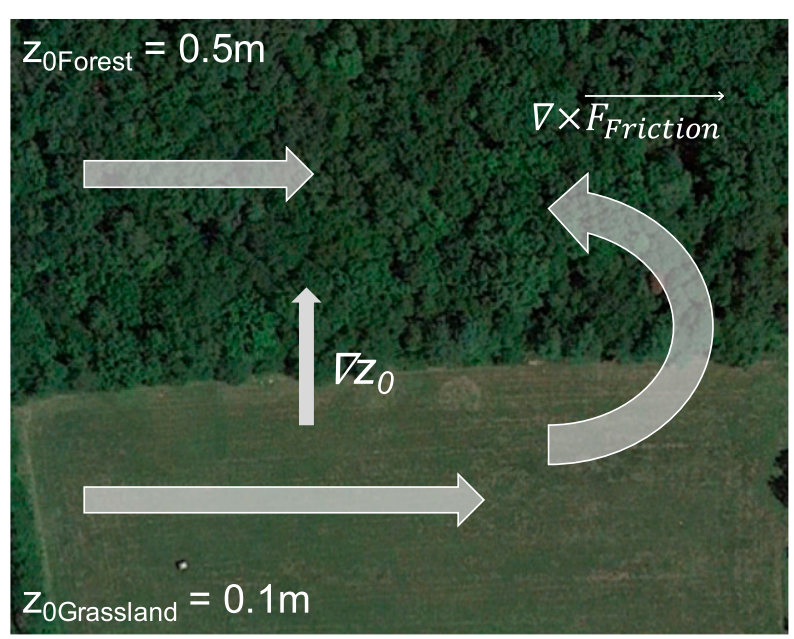

Figure 2. Schematic showing the proposed interaction. A forested (high $z_{0}$, rougher) area neighbors a grassy (low $z_{0}$, smoother) area. The relative difference in $z_{0}$ creates a horizontal gradient along the two land-cover types at the surface, perpendicular to the direction of flow. The resultant curl of the friction force, depicted by the curved arrow, as low-level flow moves over the area with a horizontal gradient could aid in tornadogenesis.

proposed that when surface winds move over heterogeneous land surfaces where the gradient in $z_{0}$ is located normal to the direction of low-level flow (lowest several hundred meters of the atmosphere), then positive vertical vorticity could be produced above the surface. This process produces nonzero values of the vertical component of the 3D vorticity vector at the surface that may enhance tornadogenesis. Similar interactions create turbulent eddies and mixing when water or air moves over obstacles such as trees, buildings, and rocks that induce frictional drag on the fluid (air, water) creating small vortices (Stull 1988; Bou-Zeid et al. 2004). This can be explained mathematically by the friction term in the simplified vertical component of the 3D vorticity equation $\zeta$ (Bluestein 1992):

$$
\frac{D \zeta}{D t}=\hat{\mathbf{k}} \cdot \nabla \times \mathbf{F}_{\text {friction }},
$$

where all other terms are assumed to be zero, $\hat{\mathbf{k}}$ is the vertical unit vector, and $\nabla \times \mathbf{F}_{\text {friction }}$ is the curl of the friction force (Coleman and Knupp 2009). Figure 2 illustrates this process, where $\nabla z_{0}$ represents the horizontal gradient in $z_{0}$ along a rough forested area $\left(z_{0}=0.5 \mathrm{~m}\right)$ adjacent to a smoother grassland $\left(z_{0}=0.1 \mathrm{~m}\right)$ area. The arrows represent differing velocity vectors and the resultant curl of the friction force as low-level flow moves over the area with a horizontal gradient in $z_{0}$. The resultant curl, shown by the curved arrow, indicates a location where tornadogenesis could be aided.

Although both the horizontal and vertical components of the vorticity vector require consideration, we focus herein on the generation of the vertical component of vorticity $\zeta$ within the lowest several hundred meters of the atmosphere, that is, 

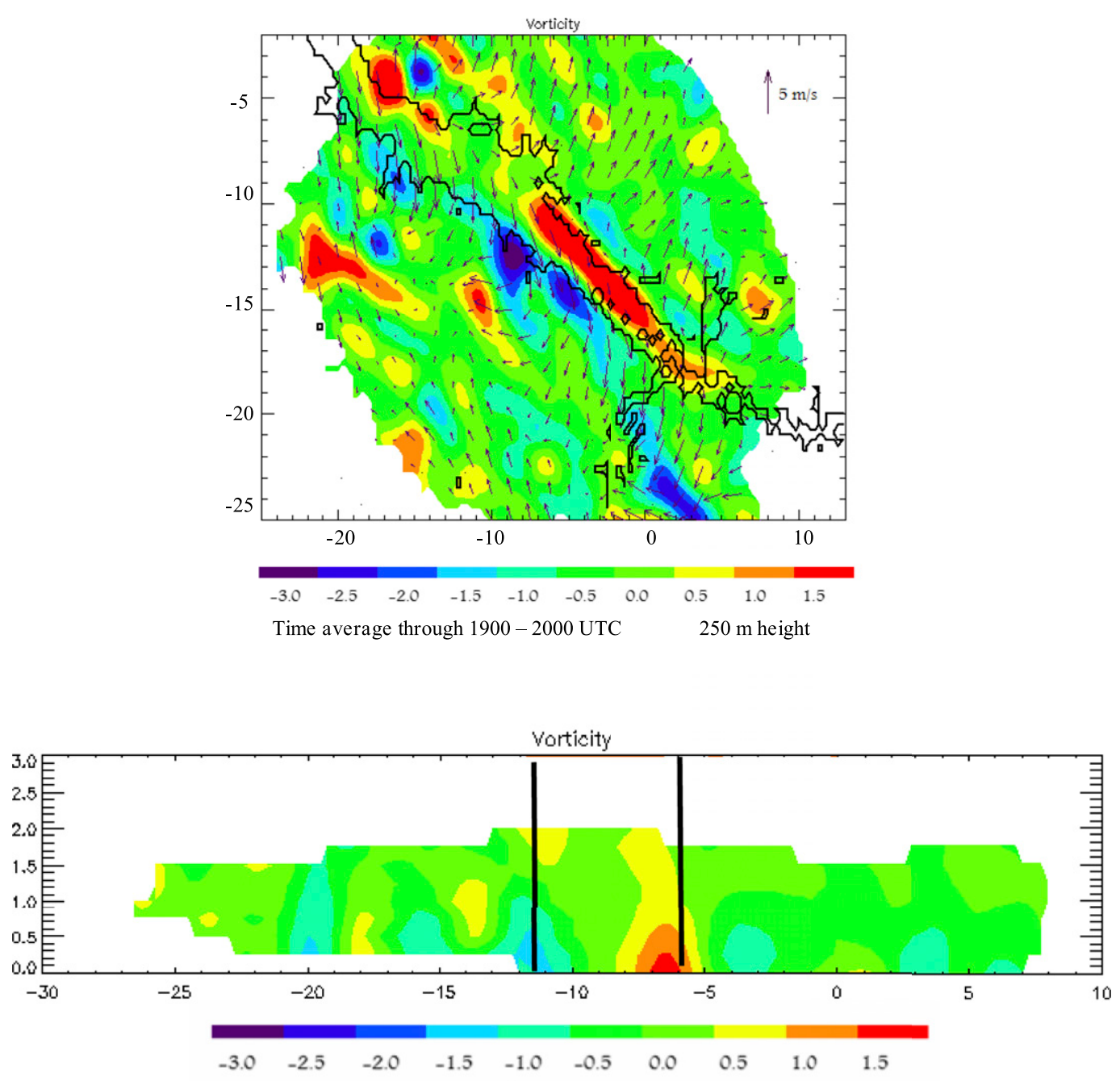

Time average through $1900-2000$ UTC

Figure 3. Hourly time averages of vertical vorticity derived from a dual-Doppler analysis of a lake breeze. (top) Horizontal flow perturbation vectors and vertical vorticity at $250-\mathrm{m}$ height. (bottom) A vertical section of vorticity along $y=-10$. Black vertical solid lines indicate the lake boundaries within the vertical section. The mean boundary layer flow was about $5 \mathrm{~m} \mathrm{~s}^{-1}$ from about $310^{\circ}$, approximately parallel to the lake axis. Taken from Asefi-Najafabady et al. (2010).

the surface layer to lower boundary layer. It is recognized that the magnitude of horizontal vorticity associated with vertical wind shear, and $\zeta$ within supercell mesocyclones or QLCS mesovortices, is $10^{-2} \mathrm{~s}^{-1}$. The magnitude of $\zeta$ produced by horizontal gradients in $z_{0}$ associated with a water-land interface, documented by Asefi-Najafabady et al. (2010) for a moderate wind case (e.g., $5 \mathrm{~m} \mathrm{~s}^{-1}$ wind speed), can exceed $10^{-3} \mathrm{~s}^{-1}$ over a significant depth of the ABL (Figure 3). This value could conceivably approach $5 \times 10^{-3} \mathrm{~s}^{-1}$ for stronger surface-layer flow on 
much smaller scales on the order of $100 \mathrm{~m}$. For example, a surface-layer wind differential of $5 \mathrm{~m} \mathrm{~s}^{-1}$ over a $500-\mathrm{m}$ horizontal scale yields a $\zeta$ magnitude of $10^{-2} \mathrm{~s}^{-1}$. Values of around this magnitude are common along the leading edge of QLCSs, and within some well-defined cold fronts and outflow boundaries associated with mesocyclones (Marquis et al. 2007).

Laboratory simulations and numerical modeling studies have also investigated the influence that land surface roughness heterogeneities have exerted on surface flow, and have demonstrated that changes in the land surface contribute to production of vorticity and generation of tornado-like flows, illustrating a need for further investigation (Dessens 1972; Avissar and Pielke 1989; Natarajan and Hangan 2009; Kellner and Niyogi 2014; Liu and Ishihara 2016; Wang et al. 2017).

\subsection{Methods to derive $z_{0}$}

Approaches to derive and represent $z_{0}$ for research and modeling purposes include using lookup tables, satellite-derived land surface and vegetation parameters, and hybrid approaches. Traditional atmospheric modeling techniques implement lookup tables that equate a land-cover class to a representative $z$ value derived from field observations (Borak et al. 2005; Jasinski et al. 2006; Zheng et al. 2014). These approaches fail to capture variation within land-cover classes and account for seasonal vegetation changes, resulting in errors in heat fluxes and skin temperature values used in weather forecasting models (Zheng et al. 2014). Alternatively, remote sensing methods have been used to relate satellite observations and ancillary data to better capture the spatial and temporal variability of $z_{0}$. Hybrid approaches using the Moderate Resolution Imaging Spectroradiometer (MODIS) vegetation indices and lookup tables have been proposed by Wu et al. (2015), Borak et al. (2005), Jasinski et al. (2006), and Jasinski et al. (2005). Backscatter caused by variation in the land surface measured by spaceborne radiometers, such as QuikSCAT, have been used to quantify roughness (Goodberlet and Mead 2014; Bergen et al. 2009). Zhang et al. (2004) implemented a multisensor approach using RADARSAT synthetic aperture radar (SAR), Landsat 5 Thematic Mapper (TM) and Landsat 7 Enhanced Thematic Mapper Plus (ETM+) data. The SAR and lidar data approaches have been developed to capture the roughness of land-cover types such as bare soil, ice, and urban areas, which are difficult to model (Chen et al. 2009; Rees and Arnold 2006; Rivas et al. 2006).

Atmospheric models implement $\mathrm{z}_{0}$ parameterization schemes to account for energy transfer and interaction between the land surface and atmosphere using lookup table values and satellite retrievals. The Noah land surface model (LSM) (Chen et al. 1996; Ek et al. 2003) is widely used as the land surface component for regional and global weather forecasting models at the National Centers for Environmental Prediction and by the Weather Research and Forecasting (WRF) Model at the National Center for Atmospheric Research (Zheng et al. 2014). The Noah LSM parameterization scheme may fail to accurately capture $z_{0}$ ranges given its reliance on land-class-based lookup table values and time-series-derived $z_{0}$ ranges, which in some cases offer constant values of land-cover classes. Nevertheless, the Noah LSM scheme was used to quantify $z_{0}$ across the study area because it offers a hybrid approach using land surface remote sensing data and lookup table values that are implemented widely across modeling applications, and accounts for 


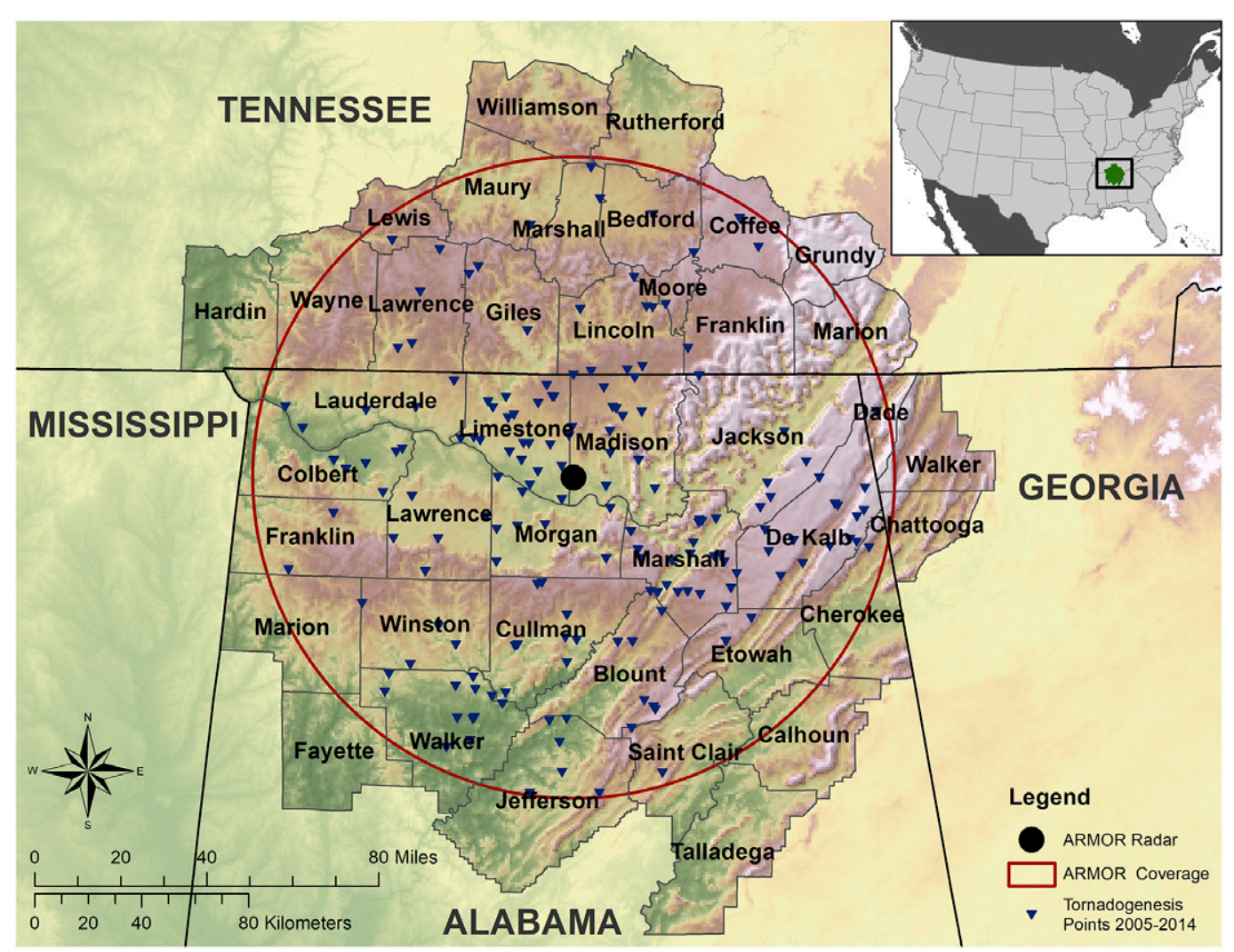

Figure 4. The area of focus for this study spans across the ARMOR coverage area. The black dot indicates the location of the ARMOR, and the red circle outlines its $120-\mathrm{km}$ scan range.

seasonal vegetation variation (Zheng et al. 2014; Chen and Zhang 2009; Ek et al. 2003; Niu et al. 2011).

\subsection{Study area and period}

The ARMOR is a scanning dual-polarimetric Doppler radar operated by the UAH Department of Atmospheric Science (University of Alabama in Huntsville 2004). ARMOR is located at the Huntsville International Airport and typically scans a 120-km range across north Alabama and portions of Tennessee and Georgia. The study area (Figure 4) is located west of the southern Appalachian Mountains covering portions of the Cumberland Plateau and Tennessee River valley with topography ranging approximately $80-700 \mathrm{~m}$ in elevation.

The study area is classified as humid subtropical under the Köppen climate classification scheme (Kottek et al. 2006). During the March-May severe weather season, the climate is warm and humid with average 3-month temperatures near $60^{\circ} \mathrm{F}$ and a relative humidity of $70 \%$ (NCDC 2018). In the fall and, primarily, the spring, severe weather and tornadoes are most prevalent; however, thunderstorms 
Earth Interactions • Volume 23 (2019) • Paper No. 5 • Page 9

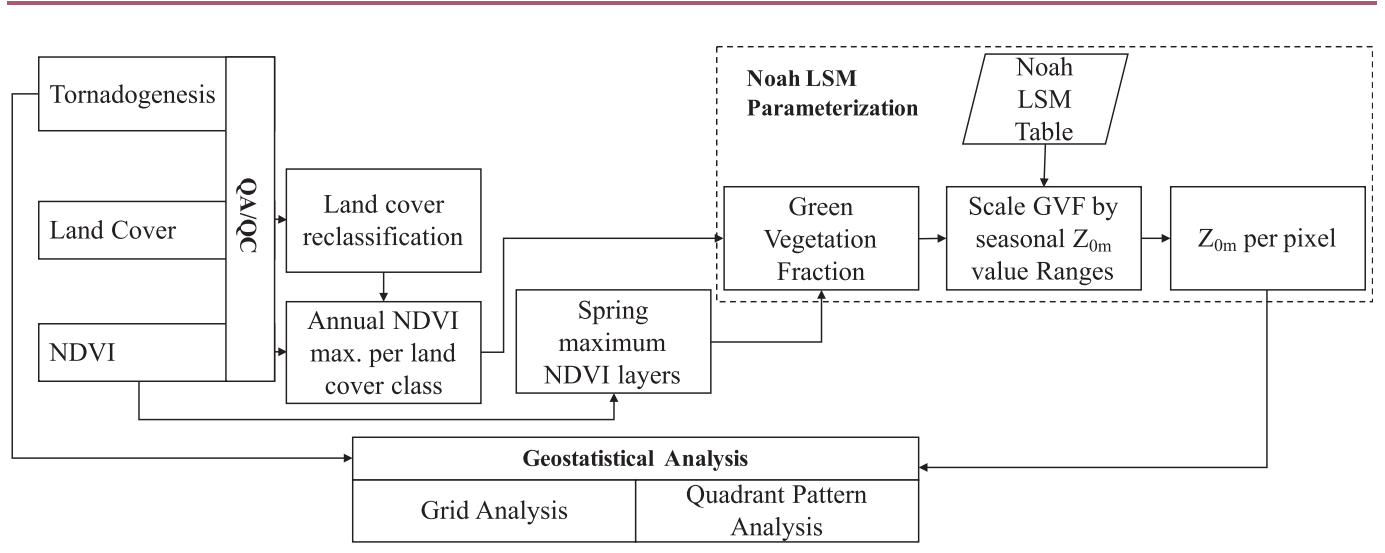

Figure 5. Flowchart showing the data preprocessing, Noah LSM parameterization scheme, and statistical approaches implemented in this study.

occur throughout the summer with 50-60 thunderstorm days observed each year (Burt and Stroud 2007). During the spring tornado months, conditions are very dynamic with respect to the emergence of vegetation following the winter months. The tornado events used in this study (shown in Figure 4 as inverted triangles) included all tornadoes that occurred within $120 \mathrm{~km}$ of the ARMOR radar over the 2005-14 period during March-May, the climatological peak in tornado occurrence within the state of Alabama (NWS 2018).

\section{Data and methods}

This study combines geospatial data, satellite remote sensing retrievals, and the Noah LSM parameterization scheme to capture $z_{0}$ variation within the ARMOR coverage area and assesses its relationship to tornadogenesis locations of weakintensity tornadoes (EF0-EF1). The selected datasets represent locations of tornadogenesis, land cover, and vegetation cover. The Noah LSM was used to parameterize $z_{0}$, followed by a geostatistical analysis to assess the spatial relationships between tornadogenesis locations and $z_{0}$ variability. A $z_{0}$ layer was created at two spatial resolutions to assess relationships between larger-scale $(500 \mathrm{~m})$ and smaller-scale features $(30 \mathrm{~m})$ surrounding tornadogenesis locations. An overview of the data and methods used in this study is shown in Figure 5 and outlined in the proceeding section.

\subsection{Tornado database}

The NOAA Storm Prediction Center (SPC) SVRGIS tornado-track dataset (NOAA 2015) and the unpublished UAH Department of Atmospheric Science tornado event catalog (University of Alabama in Huntsville 2014, unpublished material, accessed 1 June 2014) were used to identify tornadogenesis locations and information on maximum tornado intensity, wind speed, fatalities, and injuries. Each dataset is compiled from National Weather Service storm reports; however, the UAH catalog is a spatial and temporal subset of the SVRGIS dataset containing 
Earth Interactions • Volume 23 (2019) • Paper No. 5 • Page 10

only tornado events that initiated within the ARMOR radar coverage area from 2005 to 2014. These two datasets were quality controlled by cross comparing event information to identify errors before plotting the tornadogenesis point locations. The points were then filtered to identify EF0-EF1 tornadogenesis events during the study period that initiated within the study area, leaving 131 tornadogenesis points.

Several tornadoes produced during the 25-27 April 2011 tornado outbreak and other events left behind tornado scars (long-lasting damage to vegetation, especially trees) that greatly altered the land cover and were captured by the MODIS and Landsat retrievals. The $z_{0}$ parameterization scheme is dependent on representative land cover and vegetation for the spring tornado seasons of 2006 and 2011, thus tornadogenesis locations occurring between 2005 and 2008 correspond to 2006 land cover and those occurring between 2009 and 2014 correspond to 2011 land cover. Changes to the underlying land features affect the accuracy of the $z_{0}$ representation particularly for tornadogenesis events that occurred before the tornado scars were made and captured within the 2011 land cover (from 2009 to 27 April 2011), thus, it was necessary to correct for these changes in $z_{0}$. The NOAA geospatial tornado-track survey data for 25-27 April 2011 produced by NWS Birmingham (2011) offers detailed tornado swath information. These data were used to identify significant (EF4-EF5) tornado events that occurred within 0-4 km of a tornadogenesis location. Tornadogenesis events within the 2011 sample group occurring from 2009 to 27 April 2011 within a 4-km area of a significant tornado event were omitted from this study. A total of 6 tornadoes from the 2011 sample group were removed reducing the final sample size to 125 tornadogenesis points.

\subsection{Land cover and reclassification}

Data acquired from the Multi-Resolution Land Characteristics Consortium (MRLC) National Land Cover Database (NLCD) served as the high-resolution 30m land-cover layer (Homer et al. 2011; Fry et al. 2006). NLCD data are derived from Landsat imagery and use a 16-class land-cover classification scheme based on the Anderson et al. (1976) scheme containing an accuracy of 84\% (Wickham et al. 2013). Spatial variations in land-cover type are minimal seasonally and annually, thus NLCD land cover is produced in 5-yr intervals. The 2006 and 2011 datasets provided representative land cover for two time spans of tornadogenesis points: 2005-08 for the 2006 dataset and 2009-14 for the 2011 NLCD dataset.

The MODIS collection 5 level 3 annual 500-m land-cover composite product, MCD12Q1, is derived from the MODIS sensor aboard the Aqua and Terra satellites, with class accuracy between $72 \%$ and $75 \%$, provided a medium-resolution land-cover representation (Friedl et al. 2010; Strahler et al. 1999; Friedl and Sulla-Menashe 2015). MODIS land-cover data for 2006 and 2011 were acquired from the Land Processes Distributed Active Archive Center (LP DAAC) to align with the NLCD land-cover data. The IGBP classification scheme was selected because it was developed to represent land classes most useful across modeling disciplines Strahler et al. (1999).

The Noah LSM combines remote sensing measurements and $z_{0}$ values associated with the 17-class MODIS IGBP or 24-class USGS land-cover classification schemes. The NLCD land-cover data were reclassified to match the 24 USGS land-cover classes, with the exception of the urban areas. The NLCD urban land-cover classes capture four development classes that vary widely in $z_{0}$ : open space, low intensity, 
Earth Interactions - Volume 23 (2019) • Paper No. 5 • Page 11

medium intensity, and high intensity. Because $z_{0}$ values for these classes are not part of the Noah LSM USGS classification scheme, associated $z_{0}$ value ranges were determined from the Vickery et al. (2006) and Simpson et al. (2012) predefined parameters.

\subsection{NDVI and GVF data, analysis, and corrections}

The vegetation of the study area was represented using normalized difference vegetation index (NDVI) datasets derived from two satellite instruments. The Terra MODIS, version 3, 500-m MOD13A1 product (Didan 2015) was acquired from the LP DAAC for the full years of 2006 and 2011. This NDVI data layer contains an accuracy within \pm 0.025 and was quality controlled to remove pixels under clouds and cloud shadow that cause brightening and darken effects, respectively, reducing the accuracy of atmospheric correction and computed NDVI values (Huete et al. 1999; MODIS Land Team 2016; Zhu and Woodcock 2012).

The U.S. Geological Survey (USGS) Landsat Surface Reflectance Level-2 Science Product data (USGS 2011, 2006) were acquired from the Earth Resources Observation and Science (EROS) Center Science Processing Architecture (ESPA) interface (USGS 2019a,b). For this data product, the 6S radiative transfer model (Vermote 1997) was applied to Landsat 4-7 retrievals, from which NDVI and quality assessment (QA) bands are derived. For this study, 286 Landsat 7 ETM+ and Landsat 5 TM images with $60 \%$ cloud clover or less were acquired for 2006 and 2011. The NDVI data were quality controlled using the QA bands to remove contaminated pixels caused by oversaturation, cloud cover, and cloud shadow established by Zhu and Woodcock (2012), Arvidson et al. (2001), Arvidson et al. (2000), and Simpson and Stitt (1998).

The Noah LSM uses green vegetation fraction (GVF) to quantify and control water and energy transfer between the land surface and the atmosphere and capture seasonal variations in $z_{0}$ over vegetated areas (Zeng et al. 2000). To determine $z_{0}$ of a particular area, the GVF is determined using

$$
\mathrm{GVF}=\frac{\mathrm{NDVI}-\mathrm{NDVI}_{\text {in }}}{\mathrm{NDVI}_{\max }-\mathrm{NDVI}_{\min }},
$$

where NDVI is the NDVI value of a specific pixel at a point in time, $\mathrm{NDVI}_{\min }$ is the constant minimum NDVI value for bare soil (0.01), and $\mathrm{NDVI}_{\max }$ is the maximum NDVI for a land-cover class over a period of time.

A temporal analysis of the NDVI values was performed to determine the $\mathrm{NDVI}_{\text {max }}$ for USGS and IGBP land-cover types in the study area. Two full years of MODIS and Landsat NDVI data were analyzed to ensure values captured vegetative ranges across multiple years. NDVI pixel values for each land-cover class were extracted for the study area to which a histogram thresholding method by Zeng et al. (2000) and Gutman and Ignatov (1998) was applied to account for pixel contamination near land-cover -class boundaries. The $\mathrm{NDVI}_{\max }$ values from the sample were selected as follows: 90th-percentile value for sparsely vegetated areas (e.g., urban and bare soil) and the 75th-percentile value for vegetated areas. The highest NDVI $_{\max }$ values across 2006 and 2011 are shown in Table 1.

The NDVI variable in Equation (4) was sampled from NDVI values for the climatological peak spring tornado season for north Alabama (March-May). Representative spring layers for the Landsat and MODIS NDVI were generated 


\section{Earth Interactions - Volume 23 (2019) • Paper No. 5 - Page 12}

Table 1. Lookup table for $Z_{0 m}$ listing parameters used to determine $G V F$ and $Z_{0 m}$ for the MODIS and Landsat data.

\begin{tabular}{|c|c|c|c|c|c|c|c|}
\hline $\begin{array}{l}\text { Mapped USGS land } \\
\text { cover }\end{array}$ & $Z_{0 \mathrm{~m}, \min }$ & $Z_{0 \mathrm{~m}, \max }$ & $\mathrm{NDVI}_{\text {max }}$ & IGBP land cover & $Z_{0 \mathrm{~m}, \min }$ & $Z_{0 \mathrm{~m}, \max }$ & $\mathrm{NDVI}_{\text {max }}$ \\
\hline Water bodies & 0.0001 & 0.0001 & 0.631 & Water & 0.0001 & 0.0001 & 0.895 \\
\hline $\begin{array}{l}\text { Urban: developed, } \\
\text { open space }\end{array}$ & 0.03 & 0.03 & 0.884 & $\begin{array}{l}\text { Evergreen needleleaf } \\
\text { forest }\end{array}$ & 0.5 & 0.5 & 0.912 \\
\hline $\begin{array}{l}\text { Urban: developed, low } \\
\text { intensity }\end{array}$ & 0.15 & 0.15 & 0.821 & $\begin{array}{l}\text { Evergreen broadleaf } \\
\text { forest }\end{array}$ & 0.5 & 0.5 & 0.902 \\
\hline $\begin{array}{l}\text { Urban: developed, } \\
\text { medium intensity }\end{array}$ & 0.35 & 0.35 & 0.721 & $\begin{array}{l}\text { Deciduous needleleaf } \\
\text { forest }\end{array}$ & 0.5 & 0.5 & 0.948 \\
\hline $\begin{array}{l}\text { Urban: developed, high } \\
\text { intensity }\end{array}$ & 0.5 & 0.5 & 0.593 & $\begin{array}{l}\text { Deciduous broadleaf } \\
\text { forest }\end{array}$ & 0.5 & 0.5 & 0.948 \\
\hline $\begin{array}{l}\text { Barren or sparsely } \\
\text { vegetated }\end{array}$ & 0.01 & 0.01 & 0.858 & Mixed forest & 0.2 & 0.5 & 0.953 \\
\hline $\begin{array}{c}\text { Deciduous broadleaf/ } \\
\text { needleleaf forest }\end{array}$ & 0.5 & 0.5 & 0.921 & Closed shrublands & 0.01 & 0.05 & 0.895 \\
\hline $\begin{array}{c}\text { Evergreen broadleaf/ } \\
\text { needleleaf forest }\end{array}$ & 0.5 & 0.5 & 0.892 & Open shrublands & 0.01 & 0.06 & 0.714 \\
\hline Mixed forest & 0.2 & 0.5 & 0.906 & Woody savannas & 0.01 & 0.05 & 0.940 \\
\hline Shrubland & 0.01 & 0.05 & 0.914 & Savannas & 0.15 & 0.15 & 0.900 \\
\hline Grassland & 0.1 & 0.12 & 0.877 & Grasslands & 0.1 & 0.12 & 0.920 \\
\hline $\begin{array}{l}\text { Dryland cropland and } \\
\text { pasture }\end{array}$ & 0.05 & 0.15 & 0.862 & Permanent wetlands & 0.3 & 0.3 & 0.931 \\
\hline Croplands (MODIS) & 0.05 & 0.15 & 0.889 & Croplands & 0.05 & 0.15 & 0.939 \\
\hline Wooded wetland & 0.4 & 0.4 & 0.914 & Urban and built-up & 0.5 & 0.5 & 0.914 \\
\hline \multirow[t]{2}{*}{ Herbaceous wetland } & 0.2 & 0.2 & 0.872 & $\begin{array}{l}\text { Cropland/natural } \\
\text { vegetation mosaic }\end{array}$ & 0.05 & 0.14 & 0.942 \\
\hline & & & & $\begin{array}{l}\text { Barren or sparsely } \\
\text { vegetated }\end{array}$ & 0.01 & 0.01 & 0.810 \\
\hline
\end{tabular}

for 2006 and 2011 by determining the maximum NDVI for each pixel across the spring months. The maximum spring NDVI provided the best NDVI representation for the study area that corrected striping from the 2003 Landsat 7 ETM+ sensor scan line corrector failure without interpolating Landsat retrievals. Once the NDVI was determined, GVF was calculated for 2006 and 2011 shown in Figure 6.

\subsection{Noah LSM parameterization and $z_{0}$ calculations}

The Noah LSM uses two types of roughness values to account for the heat transfer $Z_{0 \mathrm{~h}}$ between the land surface and low-tropospheric levels, and momentum transfer using a momentum roughness length $Z_{0 \mathrm{~m}}$. This study uses the generalized version of the Monin-Obukhov similarity theory that assumes $Z_{0 \mathrm{~h}}=Z_{0 \mathrm{~m}}$ and implements the $Z_{0 \mathrm{~m}}$ parameterization scheme, from here on out we refer to roughness as $Z_{0 \mathrm{~m}}$ (Brutsaert 1982; Niu et al. 2011). The Chen and Zhang (2009) implementation of the Noah LSM $Z_{0 \mathrm{~m}}$ parameterizations scheme was selected since it was found to consistently perform better over changing surface conditions and seasons (Zheng et al. 2014). This approach uses the aforementioned $Z_{0 \mathrm{~m}}$ lookup table values (Table 1) and the GVF to solve for $Z_{0 \mathrm{~m}}$ : 


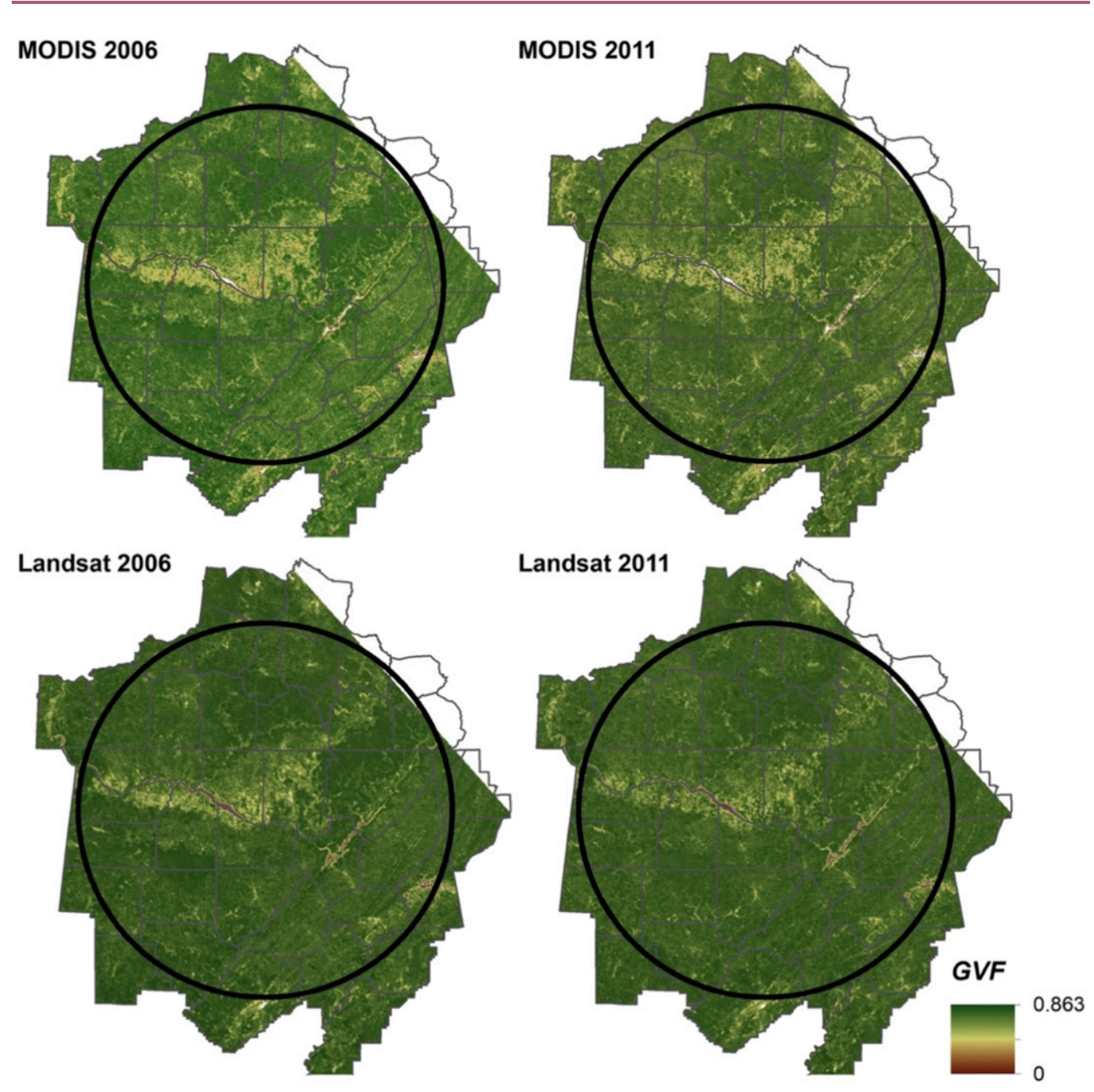

Figure 6. Derived green vegetation fraction (GVF) layers for March-May 2006 and 2011 showing (top) MODIS and (bottom) Landsat.

$$
Z_{0 \mathrm{~m}}=(1-\mathrm{GVF}) Z_{0 \mathrm{~m}, \min }+\mathrm{GVFZ}_{0 \mathrm{~m}, \max },
$$

where GVF is the spring layers calculated in the previous section, $Z_{0 \mathrm{~m} \text {, min }}$ is the minimum seasonal roughness length value in meters, and $Z_{0 \mathrm{~m} \text {,max }}$ is the maximum seasonal roughness length value in meters. This equation was applied to generate four corresponding $Z_{0 \mathrm{~m}}$ layers based on each pixel's land-cover class using the GVF and the variables outlined in Table 1 . The final $Z_{0 \mathrm{~m}}$ layers for the 2006 and 2011 Landsat and MODIS data are shown in Figure 7.

\subsection{Spatial analysis architecture}

A two-part methodology was developed to assess spatial relationships between locations of tornadogenesis and surrounding $Z_{0 \mathrm{~m}}$ variation and patterns. A gridcell 


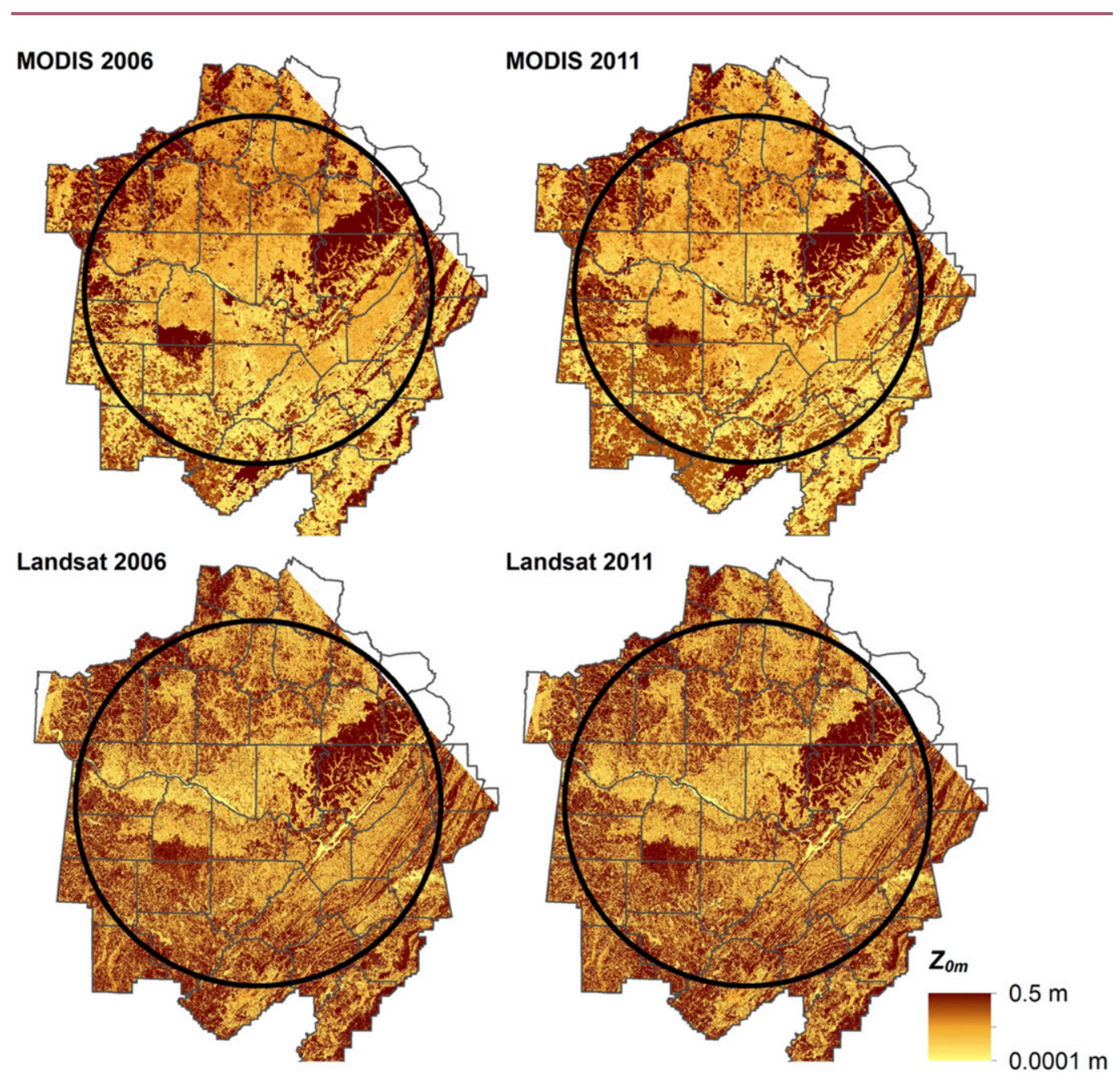

Figure 7. (†op) MODIS- and (bottom) Landsat-based $Z_{0 m}$ for March-May 2006 and 2011.

analysis was conducted to acquire a qualitative overview of the variation in $Z_{0 \mathrm{~m}}$ observed by the MODIS and Landsat instruments to evaluate patterns captured across different satellite instruments on equal-area grids. To quantify the observed patterns, a quadrant pattern analysis was used to determine the significance of the observed patterns. ArcGIS was used in both these analyses to construct the grids and quadrants and perform the geospatial statistics.

\subsubsection{Gridcell analysis}

An analytical constraint was set to focus this investigation on local mesoscale features surrounding each tornadogenesis, or tornado-track initiation point location. Mesoscale interactions occur within a 2-2000-km horizontal scale; therefore, anything below this threshold is considered microscale (Orlanski 1975). A 4-km threshold surrounding each tornadogenesis point was selected based on $4 \mathrm{~km}$ being 
Earth Interactions - Volume 23 (2019) • Paper No. 5 • Page 15

the coarsest spatial resolution used in convection allowing mesoscale models such as the WRF Nonhydrostatic Mesoscale Model and Advanced Research WRF, and this threshold being close to the approximate microscale where the proposed tornadogenesis processes occur (Markowski and Richardson 2009). The minimum gridcell dimension was set to $500 \mathrm{~m}$, the spatial resolution of the MODIS data, enabling the comparison of the different resolution data across equal spatial scales. Grids with $500 \mathrm{~m} \times 500 \mathrm{~m}$ cells within an $8 \mathrm{~km} \times 8 \mathrm{~km}$ area surrounding each tornadogenesis point were created and oriented along each tornadogenesis point associated tornado track bearing direction $\theta$, which is used as a proxy for surfacelevel flow recognizing there is a $45^{\circ}$ offset between surface flow and tornado-track orientation. Figure 8 provides a schematic of one of the 125 resultant grids, where the tornadogenesis location is shown as the black dot, surrounded by 256 grid cells within a $64-\mathrm{km}^{2}$ area. For each tornadogenesis point grid, the $Z_{0 \mathrm{~m}}$ pixel values falling within each grid cell were averaged for the Landsat and MODIS data. These 125 MODIS and 125 Landsat grids were then averaged across the sample for all corresponding gridcell locations to generate comparable results for the two $Z_{0 \mathrm{~m}}$ datasets outlined in the proceeding section.

\subsubsection{Quadrant pattern analysis}

Square quadrants surrounding each tornadogenesis point were separately created (in addition to the grids) using the same 500-m intervals ( $\Delta r$ and $\Delta d$ shown in Figure 9) oriented along $\theta$ from 500 to $4000 \mathrm{~m}$ in size. To generate the quadrants, the coordinates of two points along the $\theta$ axis were determined at varying alongtrack distances from the tornadogenesis location at $\Delta d$ ahead of and before the location. A schematic of this process is shown in Figure 9: the point of tornadogenesis is centered, surrounded by a point forward (after) the tornadogenesis location and a point backward (before) tornadogenesis oriented along $\theta$. From these lines and using the same 500-m intervals, square quadrants were created along each axis to a cross-track distance $r$, two before the tornadogenesis point (backward-left and backward-right quadrants), and two after tornadogenesis (forward-left and forward-right quadrant). A UTM projection was critical for determining the coordinate locations used to construct the quadrants because it offers a higher precision than degree-based projections, which reduced the resultant offset between the orientation of the constructed quadrant and the original tornado track. Similar to the grid analysis, for each quadrant the mean $Z_{0 \mathrm{~m}}$ values of pixels falling within each of the areas were sampled across all tornadogenesis locations and repeated across the four $Z_{0 m}$ layers for each variable quadrant size.

\subsubsection{Quadrant pattern groups}

Separately, a pattern analysis was used to quantify spatial patterns and variation

observed in the $Z_{0 \mathrm{~m}}$ grid analysis to determine relative differences in $Z_{0 \mathrm{~m}}$ between six predefined pattern groups, whether these differences were significant, and if significant, the relevant spatial scales they differ. The mean $Z_{0 \mathrm{~m}}$ values collected for each quadrant were combined to test six possible quadrant patterns combinations surrounding the tornadogenesis locations shown in Figure 10. For each pattern combination, the average quadrant values of $Z_{0 \mathrm{~m}}$ were separated into two 


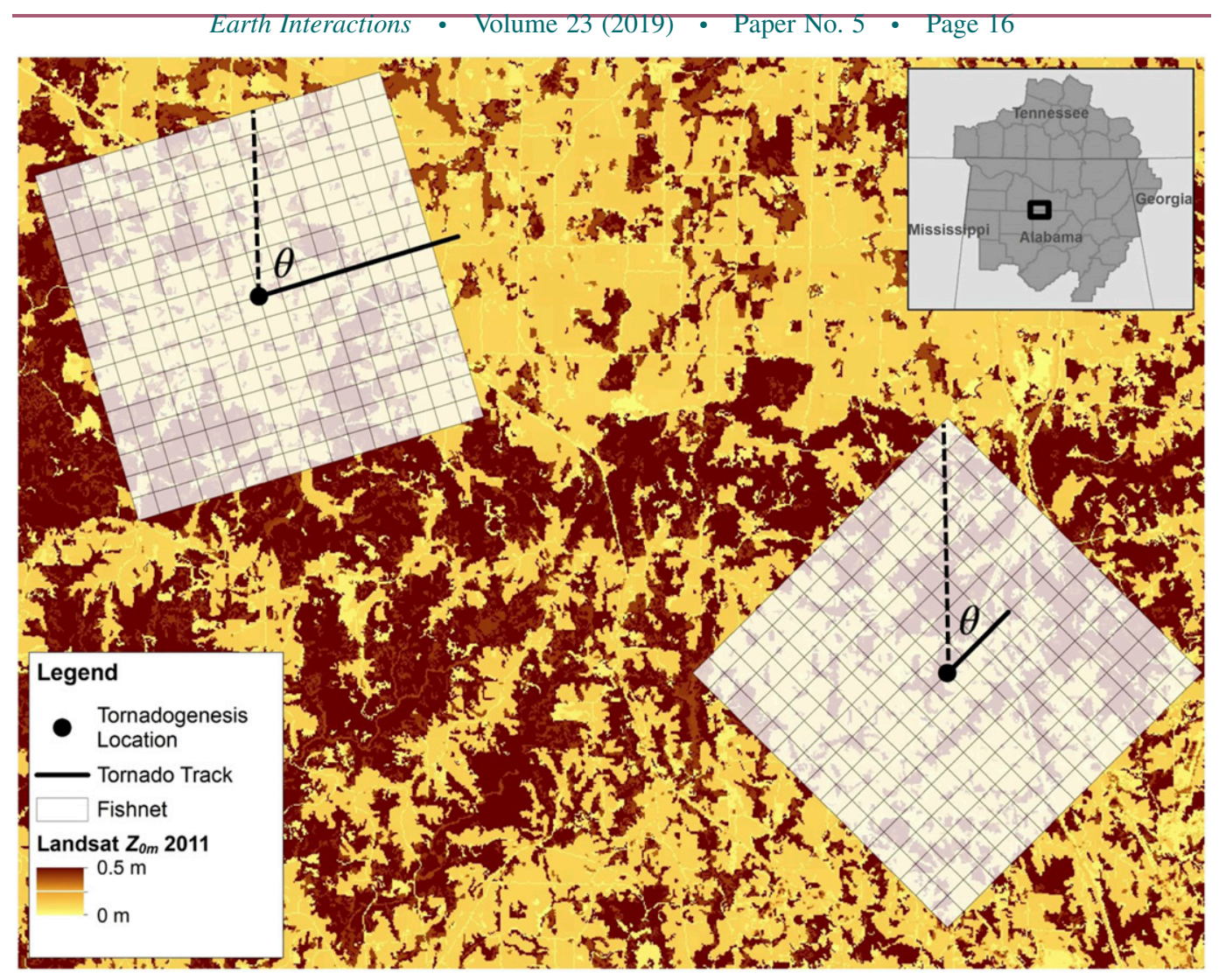

Figure 8. Example schematic showing the generated $\theta$-oriented fishnets surrounding tornadogenesis points. The black points indicate tornadogenesis locations, the solid black lines indicate the observed tornado tracks, and the dashed black lines indicate the north-south direction. The angle between the solid and dashed black lines is $\theta$. The tornado tracks and respective fishnets are overlaid on the 2011 Landsat $Z_{0 m}$ layer.

groups to compare the relative difference in the mean quadrant $Z_{0 \mathrm{~m}}$ for each pattern combination where gray represents group A and black represents group B. The quadrants were combined into two pattern groups by averaging the per-quadrant mean $Z_{0 \mathrm{~m}}$ within each pattern group. The resultant mean values of $Z_{0 \mathrm{~m}}$ for each pattern group were differenced across the 125 tornadogenesis points and spatial scales. Eight iterations of pattern differences were run for each of the six patterns for each tornadogenesis point, generating 1000 data values for each pattern group.

For each pattern and quadrant spatial scale, the collected pattern group difference values were plotted using the kernel density function (KDF) based on Parzen (1962) and Rosenblatt (1956):

$$
f_{h}=\frac{1}{n} \sum_{i=1}^{n} K_{h}\left(x-x_{i}\right)=\frac{1}{n h} \sum_{i=1}^{n} K \frac{x-x_{i}}{h}
$$

where $K$ represents the kernel, $x_{i}$ is the univariate independent variable, $h$ is the smoothing parameter called the bandwidth, $n$ represents the sample size, and $K_{h}$ is 


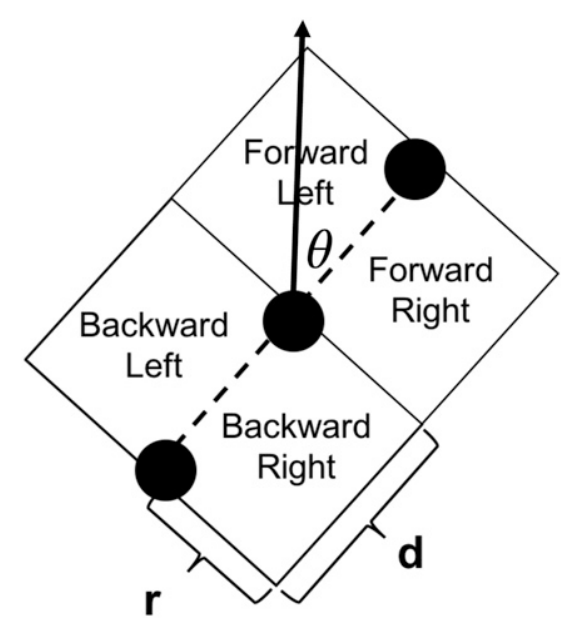

Figure 9. Quadrants around each tornadogenesis location. Each quadrant was constructed on the corresponding tornado track $\theta$ as a proxy for surface flow. Quadrants were constructed along lines at variable dimensions $r$ and $d$.

the scaled kernel. Section 4 will discuss the results of both the grid and the quadrant pattern analyses.

\section{Results and discussion}

\subsection{Grid analysis results}

The grid analysis enabled a qualitative assessment of spatial variations in $Z_{0 \mathrm{~m}}$ across two spatial scales. For each grid cell, the average $Z_{0 \mathrm{~m}}$ pixel value was extracted and averaged across the sample for MODIS and Landsat independently, shown in Figure 11, where the location of tornadogenesis (black inverted triangle), $\theta$ (solid arrow), and surface flow (dashed arrow) are depicted. The grid analysis revealed the mean $Z_{0 \mathrm{~m}}$ for Landsat to be higher than MODIS with value ranges from 0.180 to $0.228 \mathrm{~m}$ and 0.128 to $0.176 \mathrm{~m}$, respectively; however, the range for each dataset is similar, falling near $0.05 \mathrm{~m}$. The spatial variation in $Z_{0 \mathrm{~m}}$ appears similar for each sample with lower $Z_{0 \mathrm{~m}}$ located in the forward-right quadrants and higher $Z_{0 \mathrm{~m}}$ located in the other three quadrants. Most notable are the highest $Z_{0 \mathrm{~m}}$ located within the backward quadrants, primarily the backward right and along the bearing axis. The differences between the MODIS and Landsat representations of $Z_{0 \mathrm{~m}}$ are resultant from the spatial resolutions, where the MODIS representation shows larger-scale features, and more variation in $Z_{0 \mathrm{~m}}$ is observed for the Landsat data across the same general pattern. A gradient in $Z_{0 \mathrm{~m}}$ is shown to exist in the Landsat and MODIS layers perpendicular to the surface-layer wind. The tornadogenesis points are also very close to the minimum in $Z_{0 \mathrm{~m}}$ supporting the hypothesis in that a horizontal gradient exists with the potential of generating positive values of the vertical components of the $3 \mathrm{D}$ vorticity vector that may aid in tornadogenesis. This is consistent with the conceptual model shown in Figure 2. 

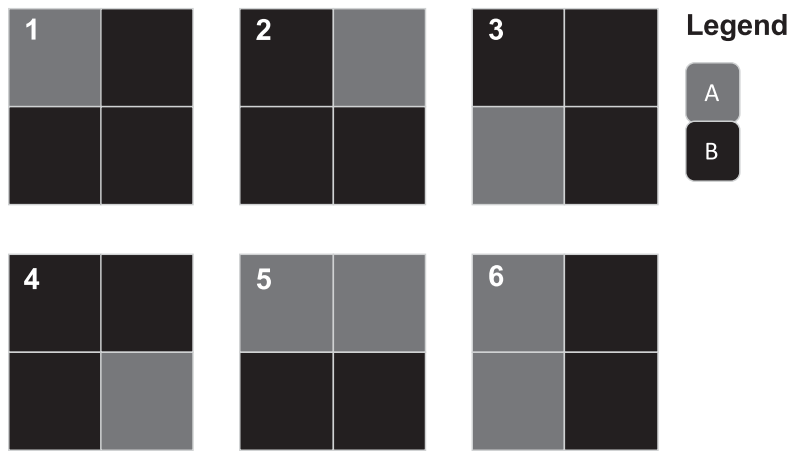

Figure 10. The six tested quadrant-pattern combinations in the pattern analysis. Gray indicates group A, and black indicates group B. To assess the difference in mean $Z_{0 m}$ between groups $A$ and $B$, the difference between the two groups was determined for each of the six patterns. The respective mean $Z_{0 m}$ for each quadrant was averaged across quadrant groups to determine a quadrant group difference value.

\subsection{Quadrant pattern analysis results}

The KDF distributions of each pattern group difference for each tornadogenesis location were computed independently for the Landsat and MODIS data to quantify observations made from the grid analysis. Plots were generated that depict a series of distribution lines, each representative of the pattern group difference values calculated across the 125 tornadogenesis locations, eight spatial scales, and the six pattern groups.

\subsubsection{Landsat results}

The Landsat KDF plots (Figure 12) reveal the distribution of pattern group difference values to become more widely distributed as the quadrant size increases. This variation likely results from the larger area sampled from which more $Z_{0 \mathrm{~m}}$ pixel values are averaged yielding greater variability and wider distributions. In addition, noticeable skewness in both larger and smaller quadrant scales are observed across several of the pattern groups, most notable in $1,2,3$, and 6 . This relative skewness implies larger differences in $Z_{0 \mathrm{~m}}$ between pattern groups across certain spatial scales further indicating horizontal gradients in $Z_{0 \mathrm{~m}}$.

The mean, standard deviation, skewness, and kurtosis were computed to further investigate the statistical significance of the KDF pattern group difference observations. A one-sample two-tailed $t$ test was performed to identify pattern groups meeting a $95 \%$ significance level with a null hypothesis that there is no difference between the two pattern groups, or that the resulting $Z_{0 \mathrm{~m}}$ difference is zero (implying a homogeneous flat surface). Otherwise, those that test as significant imply that a notable horizontal gradient exists between the two pattern groups. The statistical results for Landsat are provided in Table 2 where boldface values indicate statistical significance. 
Earth Interactions - Volume 23 (2019) - Paper No. 5 - Page 19
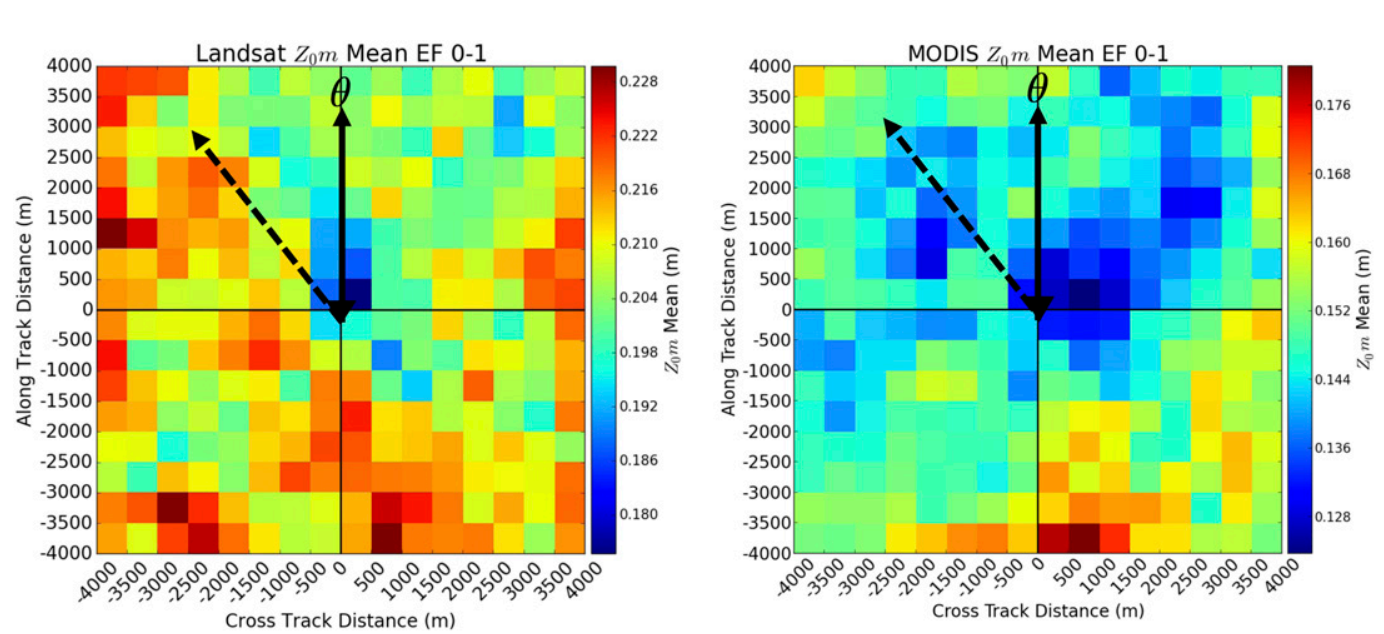

Figure 11. Grid analysis results performed on (left) Landsat and (right) MODIS data for EFO-EF1 tornadoes. The black inverted triangle identifies the tornadogenesis location, the solid arrow represents $\theta$, and the dashed arrow is the direction of surface flow.

The two-tailed $t$ test revealed two pattern groups for the Landsat data with $p$ values meeting the $95 \%$ significance level; pattern group 1 at $500 \mathrm{~m}$ had a $p$ value of 0.047 and Pattern group 6 at $4000 \mathrm{~m}$ the $p$ value was 0.045 . Further examination reveals that the distribution of values is skewed toward the positive end, meaning quadrant group $\mathrm{A}$ has a higher mean $Z_{0 \mathrm{~m}}$ value than quadrant group $\mathrm{B}$. In each of
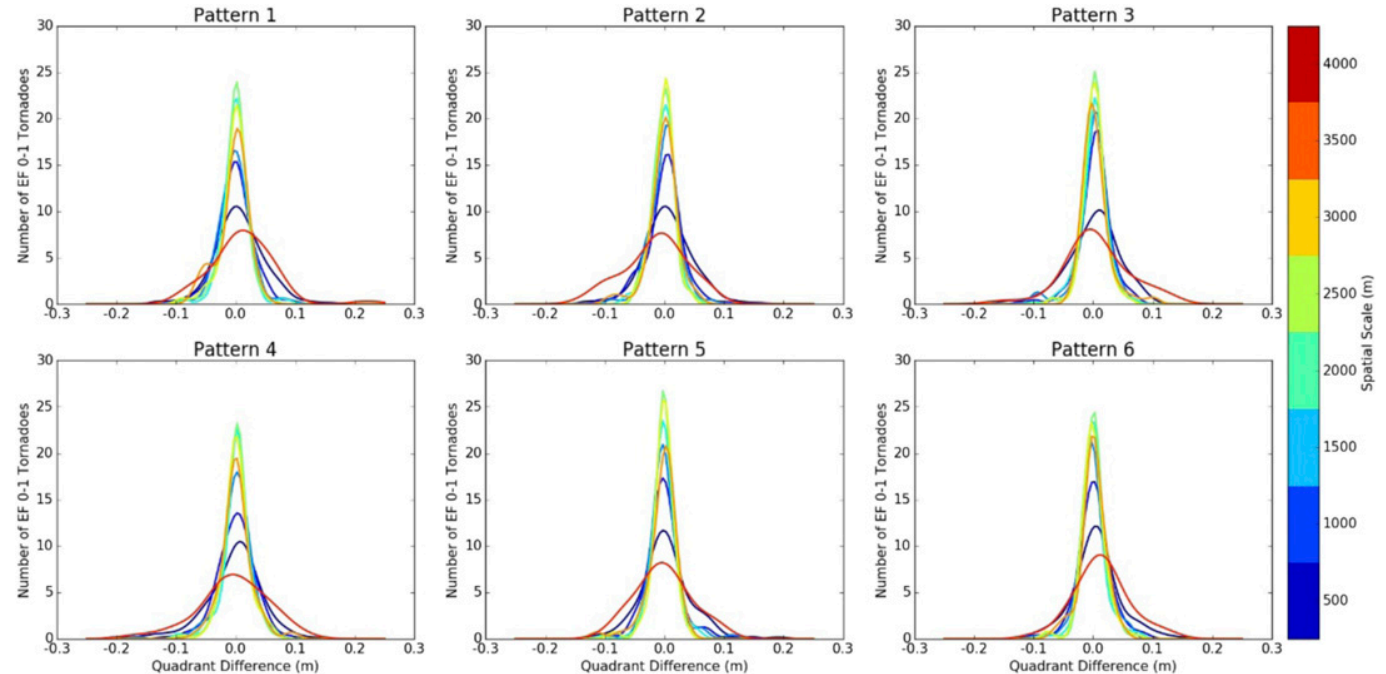

Figure 12. Landsat $Z_{0 m} K D F$ plots of the pattern group difference for EFO-EF 1 tornadoes. 
Earth Interactions - Volume 23 (2019) - Paper No. 5 • Page 20

Table 2. Landsat pattern group difference statistics table for EFO-EF1 tornadoes. Boldface values indicate statistical significance at the $95 \%$ level using a onesample two-tailed $t$ test.

\begin{tabular}{|c|c|c|c|c|c|c|c|}
\hline Statistic & Pattern 1 & Pattern 2 & Pattern 3 & Pattern 4 & Pattern 5 & Pattern 6 & Scale (m) \\
\hline Mean & 0.007 & -0.004 & 0.001 & -0.003 & 0.002 & 0.005 & 500 \\
\hline Std dev & 0.042 & 0.045 & 0.043 & 0.046 & 0.041 & 0.040 & 500 \\
\hline Skewness & 0.132 & -0.217 & -0.634 & -0.860 & 0.508 & 0.321 & 500 \\
\hline Kurtosis & 1.645 & 0.911 & 0.990 & 2.268 & 2.688 & 1.433 & 500 \\
\hline$p$ value & 0.047 & 0.217 & 0.880 & 0.459 & 0.612 & 0.092 & 500 \\
\hline Mean & -0.001 & -0.001 & 0.003 & -0.001 & -0.001 & 0.001 & 1000 \\
\hline Std dev & 0.029 & 0.032 & 0.028 & 0.034 & 0.030 & 0.028 & 1000 \\
\hline Skewness & -0.199 & -0.485 & -1.026 & -1.423 & 0.969 & -0.181 & 1000 \\
\hline Kurtosis & 1.739 & 1.916 & 4.156 & 6.945 & 5.137 & 2.510 & 1000 \\
\hline$p$ value & 0.683 & 0.728 & 0.194 & 0.703 & 0.566 & 0.517 & 1000 \\
\hline Mean & -0.001 & 0.000 & 0.001 & 0.000 & -0.001 & 0.001 & 1500 \\
\hline Std dev & 0.027 & 0.024 & 0.027 & 0.028 & 0.026 & 0.024 & 1500 \\
\hline Skewness & 0.140 & -0.306 & -1.423 & -1.551 & 0.805 & -0.186 & 1500 \\
\hline Kurtosis & 2.723 & 2.245 & 4.305 & 7.675 & 6.099 & 2.537 & 1500 \\
\hline$p$ value & 0.556 & 0.951 & 0.643 & 0.856 & 0.612 & 0.909 & 1500 \\
\hline Mean & 0.000 & -0.002 & 0.000 & 0.002 & -0.001 & 0.000 & 2000 \\
\hline Std dev & 0.022 & 0.020 & 0.023 & 0.024 & 0.021 & 0.022 & 2000 \\
\hline Skewness & 0.018 & -0.358 & -0.655 & -0.864 & -0.554 & 0.305 & 2000 \\
\hline Kurtosis & 4.385 & 1.335 & 2.762 & 3.204 & 4.601 & 4.035 & 2000 \\
\hline$p$ value & 0.946 & 0.256 & 0.916 & 0.366 & 0.374 & 0.974 & 2000 \\
\hline Mean & -0.001 & -0.002 & 0.002 & 0.001 & -0.002 & 0.001 & 2500 \\
\hline Std dev & 0.021 & 0.018 & 0.019 & 0.022 & 0.018 & 0.029 & 2500 \\
\hline Skewness & -0.981 & -0.007 & -0.257 & -0.601 & -1.046 & -0.035 & 2500 \\
\hline Kurtosis & 3.551 & 0.811 & 2.634 & 3.244 & 5.126 & 3.844 & 2500 \\
\hline$p$ value & 0.478 & 0.148 & 0.153 & 0.528 & 0.087 & 0.631 & 2500 \\
\hline Mean & -0.001 & -0.002 & 0.001 & 0.002 & -0.002 & 0.000 & 3000 \\
\hline Std dev & 0.023 & 0.018 & 0.018 & 0.022 & 0.019 & 0.021 & 3000 \\
\hline Skewness & -1.252 & -0.349 & -0.225 & -0.211 & -1.652 & -0.150 & 3000 \\
\hline Kurtosis & 3.318 & 0.618 & 2.917 & 2.905 & 6.182 & 3.753 & 3000 \\
\hline$p$ value & 0.576 & 0.275 & 0.432 & 0.415 & 0.193 & 0.960 & 3000 \\
\hline Mean & -0.004 & -0.002 & 0.004 & 0.002 & -0.005 & 0.000 & 3500 \\
\hline Std dev & 0.025 & 0.024 & 0.023 & 0.025 & 0.025 & 0.021 & 3500 \\
\hline Skewness & -0.880 & -1.271 & 2.072 & 0.776 & -2.244 & -0.641 & 3500 \\
\hline Kurtosis & 0.539 & 4.269 & 6.290 & 3.533 & 7.339 & 1.775 & 3500 \\
\hline$p$ value & 0.258 & 0.591 & 0.217 & 0.613 & 0.222 & 0.990 & 3500 \\
\hline Mean & 0.012 & -0.015 & 0.006 & -0.004 & -0.002 & 0.014 & 4000 \\
\hline Std dev & 0.052 & 0.051 & 0.054 & 0.057 & 0.046 & 0.045 & 4000 \\
\hline Skewness & 1.008 & -0.342 & -0.059 & -0.575 & 0.173 & 0.246 & 4000 \\
\hline Kurtosis & 4.276 & -0.311 & 1.195 & 0.787 & -0.235 & 0.712 & 4000 \\
\hline$p$ value & 0.114 & 0.056 & 0.463 & 0.674 & 0.791 & 0.045 & 4000 \\
\hline
\end{tabular}

these pattern groups, group A is located to the left of the tornado track bearing direction $\theta$, which was observed to be significantly higher for these specific spatial scales and pattern groups, hence rejecting that null hypothesis that a homogeneous surface surrounds the tornadogenesis locations. This result supports the assessed hypothesis revealing $Z_{0 \mathrm{~m}}$ gradients conducive for the formation of positive vertical 

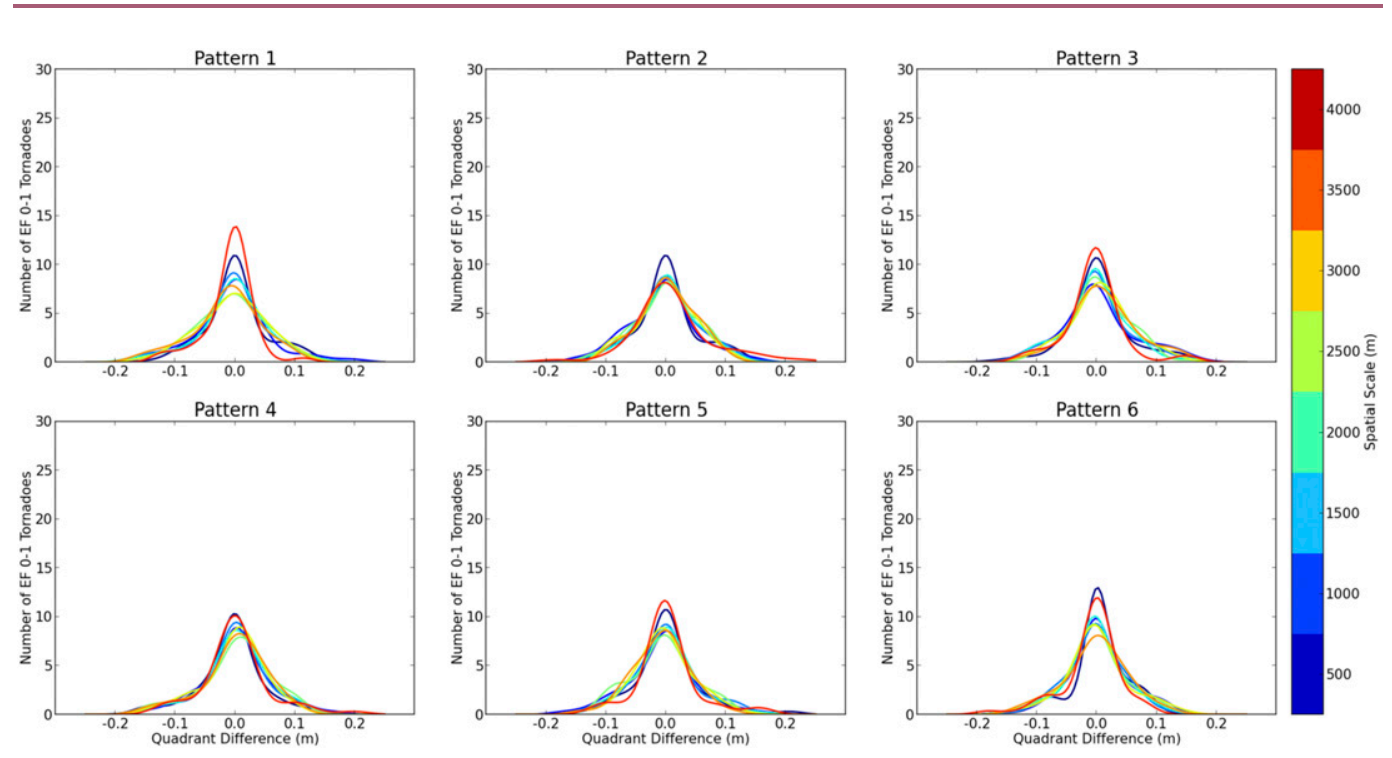

Figure 13. MODIS $Z_{0 m}$ KDF plots of the pattern group difference for EFO-EF1 tornadoes.

vorticity to form near the surface, and consistent with the findings from the grid analysis (Figure 11).

\subsubsection{MODIS results}

The MODIS KDF plots in Figure 13 reveal wider distributions than the Landsat plots and less variation across spatial scales. The tail end of most distributions reveal a smaller secondary peak for all patterns, however, the KDF distributions maximums remain centered around zero. Less variability between spatial scale and pattern groups can be attributed to the lower resolution of the MODIS data, which captured larger-scale features in the grid analysis compared to Landsat.

The two-tailed $t$ test performed on the MODIS data did not reveal any pattern combinations that met the $95 \%$ significance level in Table 3. These results were expected given the lack of qualitative skewness in the KDF plots and reveal the $500-\mathrm{m}$ MODIS data likely have a spatial resolution too coarse to study $Z_{0 \mathrm{~m}}$ variation within an $8 \mathrm{~km} \times 8 \mathrm{~km}$ area, failing to reject the null hypothesis.

\subsection{Discussion of results}

The grid and quadrant pattern analyses were performed to qualitatively and quantitatively evaluate horizontal variation in $Z_{0 \mathrm{~m}}$, and statistically identify the spatial patterns and scales with significant differences between pattern groups. The grid analysis revealed a decrease in $Z_{0 \mathrm{~m}}$ within the forward-right quadrant in the MODIS and Landsat data, with higher $Z_{0 \mathrm{~m}}$ in the backward quadrants. These results suggest that across the sample of $\mathrm{EF} 0-\mathrm{EF} 1$ tornadogenesis locations, there may be gradients in $Z_{0 \mathrm{~m}}$ conducive for the formation of positive vertical vorticity 
Earth Interactions - Volume 23 (2019) • Paper No. 5 • Page 22

Table 3. MODIS pattern group difference statistics table for EFO-EF1 tornadoes.

\begin{tabular}{|c|c|c|c|c|c|c|c|}
\hline Statistic & Pattern 1 & Pattern 2 & Pattern 3 & Pattern 4 & Pattern 5 & Pattern 6 & Scale (m) \\
\hline Mean & 0.002 & 0.000 & 0.004 & -0.006 & 0.001 & 0.004 & 500 \\
\hline Std dev & 0.051 & 0.063 & 0.055 & 0.055 & 0.055 & 0.045 & 500 \\
\hline Skewness & 0.201 & 0.347 & 0.241 & -0.210 & 0.750 & -0.513 & 500 \\
\hline Kurtosis & 0.660 & 1.346 & 2.080 & 1.516 & 3.140 & 1.678 & 500 \\
\hline$p$ value & 0.603 & 0.962 & 0.404 & 0.207 & 0.748 & 0.230 & 500 \\
\hline Mean & -0.001 & -0.007 & 0.004 & 0.003 & -0.006 & 0.003 & 1000 \\
\hline Std dev & 0.062 & 0.058 & 0.063 & 0.057 & 0.059 & 0.052 & 1000 \\
\hline Skewness & 0.527 & 0.137 & 0.432 & 0.004 & -0.040 & -0.024 & 1000 \\
\hline Kurtosis & 1.733 & 0.554 & 0.222 & 0.947 & 0.967 & 0.905 & 1000 \\
\hline$p$ value & 0.869 & 0.138 & 0.407 & 0.451 & 0.225 & 0.545 & 1000 \\
\hline Mean & -0.004 & 0.003 & -0.001 & 0.002 & -0.001 & -0.003 & 1500 \\
\hline Std dev & 0.057 & 0.053 & 0.056 & 0.054 & 0.054 & 0.048 & 1500 \\
\hline Skewness & -0.208 & 0.011 & 0.158 & -0.309 & 0.131 & -0.216 & 1500 \\
\hline Kurtosis & 1.116 & 0.440 & 0.577 & 1.350 & 0.912 & 0.616 & 1500 \\
\hline$p$ value & 0.415 & 0.478 & 0.844 & 0.713 & 0.902 & 0.370 & 1500 \\
\hline Mean & -0.003 & 0.002 & -0.001 & 0.002 & -0.001 & -0.003 & 2000 \\
\hline Std dev & 0.058 & 0.051 & 0.053 & 0.054 & 0.053 & 0.059 & 2000 \\
\hline Skewness & -0.475 & -0.109 & 0.150 & -0.401 & 0.326 & -0.206 & 2000 \\
\hline Kurtosis & 1.090 & 0.199 & 0.828 & 0.652 & 1.018 & 1.035 & 2000 \\
\hline$p$ value & 0.485 & 0.641 & 9.883 & 0.653 & 0.815 & 0.468 & 2000 \\
\hline Mean & -0.005 & -0.001 & 0.004 & 0.003 & -0.005 & -0.001 & 2500 \\
\hline Std dev & 0.058 & 0.051 & 0.051 & 0.058 & 0.054 & 0.052 & 2500 \\
\hline Skewness & -0.108 & -0.263 & 0.069 & -0.589 & 0.044 & -0.013 & 2500 \\
\hline Kurtosis & 0.023 & -0.232 & 0.375 & 0.333 & -0.256 & 0.541 & 2500 \\
\hline$p$ value & 0.251 & 0.743 & 0.321 & 0.569 & 0.246 & 0.814 & 2500 \\
\hline Mean & -0.005 & 0.001 & 0.007 & -0.002 & -0.003 & 0.001 & 3000 \\
\hline Std dev & 0.057 & 0.049 & 0.053 & 0.052 & 0.049 & 0.053 & 3000 \\
\hline Skewness & -0.276 & -0.060 & 0.061 & -0.621 & 0.067 & 0.178 & 3000 \\
\hline Kurtosis & -0.073 & -0.179 & 0.343 & 0.514 & 0.595 & 0.907 & 3000 \\
\hline$p$ value & 0.328 & 0.858 & 0.209 & 0.697 & 0.476 & 0.870 & 3000 \\
\hline Mean & -0.014 & 0.003 & 0.012 & -0.001 & -0.008 & -0.002 & 3500 \\
\hline Std dev & 0.056 & 0.046 & 0.055 & 0.054 & 0.046 & 0.052 & 3500 \\
\hline Skewness & -0.514 & -0.125 & 0.267 & -0.824 & -0.228 & -0.287 & 3500 \\
\hline Kurtosis & 0.386 & -0.202 & 0.603 & 0.932 & 0.727 & 0.380 & 3500 \\
\hline$p$ value & 0.108 & 0.698 & 0.160 & 0.939 & 0.230 & 0.844 & 3500 \\
\hline Mean & -0.009 & 0.011 & -0.004 & 0.002 & 0.002 & -0.009 & 4000 \\
\hline Std dev & 0.039 & 0.067 & 0.048 & 0.055 & 0.050 & 0.046 & 4000 \\
\hline Skewness & -0.673 & 0.733 & 0.661 & 0.829 & 0.822 & -1.356 & 4000 \\
\hline Kurtosis & 3.292 & 3.056 & 4.009 & 3.353 & 3.507 & 3.472 & 4000 \\
\hline$p$ value & 0.142 & 0.283 & 0.585 & 0.820 & 0.837 & 0.177 & 4000 \\
\hline
\end{tabular}

near the surface. Building on the grid analysis, the quadrant pattern analysis was developed to evaluate six quadrant pattern group differences across the MODIS and Landsat datasets and within varying areas surrounding each tornadogenesis location. To accomplish this, KDF plots for each pattern group and spatial scale were generated, followed by a series of statistics to test for significance. The resultant Landsat KDF plots revealed relative skewness between pattern difference groups; however, as the spatial scale increased, less skewness and wider 
Earth Interactions - Volume 23 (2019) • Paper No. 5 • Page 23

distributions were observed. In comparison, the MODIS KDF plots revealed wider distributions than Landsat with little change in the distribution width as the quadrant size increased. In addition, secondary peaks in MODIS KDF values were observed; however, the maximum of each curve was centered on zero with little relative skewness observed. The two-tailed $t$ test was performed using a $95 \%$ significance level to identify significant differences between the pattern groups tested. The test revealed two pattern groups and spatial scales with significant differences in $Z_{0 \mathrm{~m}}$ for the Landsat data; however, the MODIS statistics were unable to replicate these findings. The Landsat test identified pattern group 1 at $500 \mathrm{~m}$ and pattern group 6 at $4000 \mathrm{~m}$ to have value distributions skewed toward the positive end, meaning quadrant group $\mathrm{A}$, on the left side of the flow, has a higher mean $Z_{0 \mathrm{~m}}$ value than quadrant group B. These Landsat results found statistically significant differences in $Z_{0 \mathrm{~m}}$, supporting the grid analysis, and finding a horizontal gradient in surface roughness. This finding supports the theory that horizontal surface roughness gradients coinciding with weak-intensity tornadoes exist that may influence the vertical component of the $3 \mathrm{D}$ vorticity vector near the surface. More work is needed to investigate at what magnitude these horizontal gradients influence the $3 \mathrm{D}$ vorticity vector and tornadogenesis. Results indicate that within an $8 \mathrm{~km} \times 8 \mathrm{~km}$ area surrounding each tornadogenesis location, Landsat was able to detect more variability and smaller-scale detail because of its higher spatial resolution. The MODIS data proved useful for identifying larger-scale variation in $Z_{0 \mathrm{~m}}$; however, the variation was not statistically significant at smaller scales where resultant KDF distributions were found to be similar across the spatial scales and patterns tested. For future work, the area surrounding each tornadogenesis location should be expanded to assess results across larger grid and quadrant areas that fall within the mesoscale.

Errors in the outlined findings may result from inaccuracies in the data and methodologies implemented. First, the Noah LSM parameterization scheme may result in errors in the resultant $Z_{0 \mathrm{~m}}$ layers given its dependence on a land-classbased lookup table. In addition, the accuracy of the NDVI and land-cover classes could affect the $Z_{0 \mathrm{~m}}$ layer derived because of errors in the land-cover classification schemes, and oversaturation of NDVI values in highly vegetated areas. In final, it must be noted that the tornado dataset used does not represent all events that occurred within the study area given is it reliance on human reports, thus these data are skewed toward more populated areas with human observations and access, keeping in mind that errors in the location of the actual tornadogenesis point exist, but are unknown. Future efforts should test and compare results from alternative $Z_{0 \mathrm{~m}}$ parameterization and remote sensing approaches. In addition, it must be noted that tornadoes are highly dynamic events that rely on atmospheric as well as other environmental and land surface parameters. This first-order analysis was conducted to identify horizontal gradients on the land surface without considering the other atmospheric dynamics at hand. Further research is needed to incorporate more detailed modeling efforts and case study analysis to expand on this work.

\section{Conclusions}

The goal of this study was to determine whether horizontal gradients in land surface roughness exist surrounding locations of tornadogenesis for weak (EF0-EF1) 
tornadoes. This study found evidence of statistically significant horizontal gradients in $Z_{0 \mathrm{~m}}$ surrounding EF0-EF1 tornadogenesis locations. Observations acquired from Landsat at 30-m spatial resolution revealed statistically significant horizontal gradients $Z_{0 \mathrm{~m}}$ that may be favorable for supporting tornadogenesis. It is possible that the weaker tornadoes occur in environments that are marginally supportive of tornadogenesis and that the roughness gradient provides the forcing required for tornadogenesis in such cases. Future studies should address the physical processes using idealized numerical simulations. Additional research is needed to test the developed methodology across other geographic regions to validate this study's findings in modeling efforts. Other remote sensing and modeling schemes should be incorporated into further analysis to ensure land surface variation is captured effectively. Finally, a primarily outcome of this work was the need to expand the grid and quadrant area sampled around each tornadogenesis location in order to investigate larger-scale features captured by coarser-resolution data. These results present a case to further investigate the effect variation in land surface features has on tornado dynamics. Increased understanding of the interactions between the atmosphere and land surface will improve weather forecasting and modeling and may, in the future, lead to tornado hazard mapping techniques to aid in disaster management efforts.

Acknowledgments. We thank the University of Alabama in Huntsville Department of Atmospheric Science and Earth System Science Center for supporting this research. Additionally, thanks to Kel Markert for his technical programming support in executing this study.

\section{References}

Anderson, J. R., E. E. Hardy, J. T. Roach, and R. E. Witmer, 1976: A land use and land cover classification system for use with remote sensor data. USGS Professional Paper 964, 34 pp., https://doi.org/10.3133/pp964.

Arvidson, T., J. Gasch, and S. N. Goward, 2000: Landsat 7 automatic cloud cover assessment. Proc. SPIE, 4049, https://doi.org/10.1117/12.410358.

- - — and - 2001: Landsat 7's long-term acquisition plan-An innovative approach to building a global imagery archive. Remote Sens. Environ., 78, 13-26, https://doi.org/10.1016/ S0034-4257(01)00263-2.

Asefi-Najafabady, S., K. Knupp, U. Nair, J. Mecikalski, and R. Welch, 2010: Ground-based measurements and dual-Doppler analysis of $3 \mathrm{~d}$ wind fields and atmospheric circulations induced by a meso- $\gamma$-scale inland lake. J. Geophys. Res., 115, D23117, https://doi.org/ 10.1029/2010JD014022.

Atkins, N. T., and M. Laurent, 2009: Bow echo mesovortices. Part II: Their genesis. Mon. Wea. Rev., 137, 1514-1532, https://doi.org/10.1175/2008MWR2650.1.

Avissar, R., and R. A. Pielke, 1989: A parameterization of heterogeneous land surfaces for atmospheric numerical models and its impact on regional meteorology. Mon. Wea. Rev., 117, 2113-2136, https://doi.org/10.1175/1520-0493(1989)117<2113:APOHLS>2.0.CO;2.

Bergen, K., and Coauthors, 2009: Remote sensing of vegetation 3-D structure for biodiversity and habitat: Review and implications for lidar and radar spaceborne missions. J. Geophys. Res., 114, G00E06, https://doi.org/10.1029/2008JG000883.

Bluestein, H. B., 1992: Synoptic-Dynamic Meteorology in Midlatitudes: Observations and Theory of Weather Systems. 1st ed. Taylor \& Francis, 431 pp. 


\section{Earth Interactions • Volume 23 (2019) • Paper No. 5 • Page 25}

Borak, J. S., M. F. Jasinski, and R. D. Crago, 2005: Time series vegetation aerodynamic roughness fields estimated from MODIS observations. Agric. For. Meteor., 135, 252-268, https:// doi.org/10.1016/j.agrformet.2005.12.006.

Bou-Zeid, E., C. Meneveau, and M. B. Parlange, 2004: Large-eddy simulation of neutral atmospheric boundary layer flow over heterogeneous surfaces: Blending height and effective surface roughness. Water Resour. Res., 40, W02505, https://doi.org/10.1029/2003WR002475.

Brutsaert, W. A., 1982: Evaporation into the Atmosphere: Theory, History and Applications. Springer Science and Business Media, Vol. 1, Springer, $302 \mathrm{pp}$.

Burt, C., and M. Stroud, 2007: Extreme Weather: A Guide \& Record Book. W.W. Norton \& Company, $320 \mathrm{pp}$.

Chen, F., and Y. Zhang, 2009: On the coupling strength between the land surface and the atmosphere: From viewpoint of surface exchange coefficients. Geophys. Res. Lett., 36, L10404, https://doi.org/10.1029/2009GL037980.

— with FIFE observations. J. Geophys. Res., 101, 7251-7268, https://doi.org/10.1029/95JD02165.

Chen, Y., W. Su, J. Li, and Z. Sun, 2009: Hierarchical object oriented classification using very high resolution imagery and lidar data over urban areas. Adv. Space Res., 43, 1101-1110, https:// doi.org/10.1016/j.asr.2008.11.008.

Coleman, T. A., and K. Knupp, 2009: Radar analysis of the airflow over geographic features that may affect mesocyclone intensity and tornadogenesis. 34th Conf. on Radar Meteorology, Huntsville, AL, Amer. Meteor. Soc., P6.15, https://ams.confex.com/ams/pdfpapers/ 155703.pdf.

- and P. G. Dixon, 2014: An objective analysis of tornado risk in the United States. Wea. Forecasting, 29, 366-376, https://doi.org/10.1175/WAF-D-13-00057.1.

Conrad, D., and K. R. Knupp, 2019: Doppler radar observations of horizontal shearing instability in quasi-linear convective systems. Mon. Wea. Rev., 147, 1297-1318, https://doi.org/10.1175/ MWR-D-18-0257.1.

Davies-Jones, R., 2015: A review of supercell and tornado dynamics. Atmos. Res., 158-159, 274 291, https://doi.org/10.1016/j.atmosres.2014.04.007.

Dessens, J., 1972: Influence of ground roughness on tornadoes: A laboratory simulation. J. Appl. Meteor, 11, 72-75, https://doi.org/10.1175/1520-0450(1972)011<0072:IOGROT>2.0.CO;2.

Didan, K., 2015: MOD13A1 MODIS/Terra vegetation indices 16-day L3 global 500m SIN grid V006. NASA EOSDIS Land Processes DAAC, accessed 1 September 2014, https://doi.org/ 10.5067/MODIS/MOD13A1.006.

Ek, M., K. Mitchell, Y. Lin, E. Rogers, P. Grunmann, V. Koren, G. Gayno, and J. Tarpley, 2003 : Implementation of Noah land surface model advances in the National Centers for Environmental Prediction operational mesoscale Eta model. J. Geophys. Res., 108, 8851, https:// doi.org/10.1029/2002JD003296.

Friedl, M., and D. Sulla-Menashe, 2015: MCD12Q1 MODIS/Terra+Aqua land cover type yearly L3 global 500m SIN grid V006. NASA EOSDIS Land Processes DAAC, accessed 1 September 2014, https://doi.org/10.5067/MODIS/MCD12Q1.006.

$\longrightarrow,-$, B. Tan, A. Schneider, N. Ramankutty, A. Sibley, and X. Huang, 2010: Modis collection 5 global land cover: Algorithm refinements and characterization of new datasets. Remote Sens. Environ., 114, 168-182, https://doi.org/10.1016/j.rse.2009.08.016.

Fry, J., and Coauthors, 2006: Completion of the 2006 National Land Cover Database for the conterminous United States. Photogramm. Eng. Remote Sens., 77, 858-864.

Goodberlet, M., and J. B. Mead, 2014: A model of surface roughness for use in passive remote sensing of bare soil moisture. IEEE Trans. Geosci. Remote Sens., 52, 5498-5505, https:// doi.org/10.1109/TGRS.2013.2289979.

Gutman, G., and A. Ignatov, 1998: The derivation of the green vegetation fraction from NOAA/ AVHRR data for use in numerical weather prediction models. Int. J. Remote Sens., 19, 15331543, https://doi.org/10.1080/014311698215333. 


\section{Earth Interactions • Volume 23 (2019) • Paper No. 5 • Page 26}

Holton, J., 2004: An Introduction to Dynamic Meteorology. 4th ed. Academic Press, 130 pp.

Homer, C., and Coauthors, 2011: Completion of the 2011 National Land Cover Database for the conterminous United States-Representing a decade of land cover change information. Photogramm. Eng. Remote Sens., 81, 345-354.

Huete, A., C. Justice, and W. van Leeuwen, 1999: MODIS vegetation index (MOD13). Algorithm Theoretical Basis Doc., version 3, 129 pp., https://modis.gsfc.nasa.gov/data/atbd/atbd_ $\bmod 13 . p d f$.

Jasinski, M. F., J. Borak, and R. Crago, 2005: Bulk surface momentum parameters for satellitederived vegetation fields. Agric. For. Meteor., 133, 55-68, https://doi.org/10.1016/j.agrformet. 2005.07.017.

_ - S. Habib, J. Lundquist, R. McKellip, S. Blonski, and J. Borak, 2006: Use of satellite-derived aerodynamic roughness for improved meteorological and atmospheric transport modeling. Proc. IEEE Int. Conf. on Geoscience and Remote Sensing Symp. 2006, Denver, CO, Institute of Electrical and Electronics Engineers, 429-431, https://doi.org/10.1109/IGARSS.2006.114.

Kellner, O., and D. Niyogi, 2014: Land-surface heterogeneity signature in tornado climatology? An illustrative analysis over Indiana 1950-2012. Earth Interact., 18, https://doi.org/10.1175/ 2013EI000548.1.

Knupp, K. R., and Coauthors, 2014: Meteorological overview of the devastating 27 April 2011 tornado outbreak. Bull. Amer. Meteor. Soc., 95, 1041-1062, https://doi.org/10.1175/BAMSD-11-00229.1.

Kottek, M., J. Grieser, C. Beck, B. Rudolf, and F. Rubel, 2006: World map of the Köppen-Geiger climate classification updated. Meteor. Z., 15, 259-263, https://doi.org/10.1127/0941-2948/ 2006/0130.

Liu, Z., and T. Ishihara, 2016: Study of the effects of translation and roughness on tornado-like vortices by large-eddy simulations. J. Wind Eng. Ind. Aerodyn., 151, 1-24, https://doi.org/ 10.1016/j.jweia.2016.01.006.

Markowski, P. M., and Y. P. Richardson, 2009: Tornadogenesis: Our current understanding, forecasting considerations, and questions to guide future research. Atmos. Res., 93, 3-10, https:// doi.org/10.1016/j.atmosres.2008.09.015.

— T. Tatlee, and Y. Richardson, 2018: Tornadogenesis in the 12 May 2010 supercell thunderstorm intercepted by VORTEX2 near Clinton, Oklahoma. Mon. Wea. Rev., 146, 36233650, https://doi.org/10.1175/MWR-D-18-0196.1.

Marquis, J., Y. P. Richardson, and J. M. Wurman, 2007: Kinematic observations of misocyclones along boundaries during IHOP. Mon. Wea. Rev., 135, 1749-1768, https://doi.org/10.1175/ MWR3367.1.

MODIS Land Team, 2016: Status for: Vegetation indices (MOD13). NASA, https://landval.gsfc. nasa.gov/ProductStatus.php?ProductID=MOD13.

Natarajan, D., and H. Hangan, 2009: A numerical study on the effects of surface roughness on tornado-like flows. Preprints, 11th Americas Conf. on Wind Engineering (11ACWE), San Juan, PR, International Association for Wind Engineering, http://www.iawe.org/Proceedings/ 11ACWE/11ACWE-Natarajan.pdf.

NCDC, 2018: Climate at a Glance: Alabama. NOAA NCEI, https://www.ncdc.noaa.gov/cag/ statewide/time-series.

NCEI, 2016: U.S. tornado climatology. NOAA NCEI, https://www.ncdc.noaa.gov/climate-information/extreme-events/us-tornado-climatology.

Niu, G., and Coauthors, 2011: The community Noah land surface model with multiparameterization options (Noah-MP): 1. Model description and evaluation with local-scale measurements. J. Geophys. Res., 116, D12109, https://doi.org/10.1029/2010JD015139.

NOAA, 2015: Severe Weather GIS (SVRGIS) tornado tracks. Storm Prediction Center, Norman, OK, accessed 1 June 2014, http://www.spc.noaa.gov/gis/svrgis/.

NWS, 2018: Alabama tornado occurrences by month 1950-2017. NOAA, accessed 1 January 2015, https://www.weather.gov/bmx/tornadodb_main. 


\section{Earth Interactions - Volume 23 (2019) • Paper No. 5 • Page 27}

NWS Birmingham, 2011: Pertinent geographic information systems (GIS) data from the April 27th, 2011 tornado outbreak. NOAA, https://www.weather.gov/bmx/event_04272011gis.

Orlanski, I., 1975: A rational subdivision of scales for atmospheric processes. Bull. Amer. Meteor. Soc., 56, 527-530, https://doi.org/10.1175/1520-0477-56.5.527.

Parzen, E., 1962: On estimation of a probability density function and mode. Ann. Math. Stat., 33, 1065-1076, https://doi.org/10.1214/aoms/1177704472.

Raupach, M. R., 1994: Simplified expressions for vegetation roughness length and zero-plane displacement as functions of canopy height and area index. Bound.-Layer Meteor., 71, $211-$ 216, https://doi.org/10.1007/BF00709229.

Rees, W. G., and N. S. Arnold, 2006: Scale-dependent roughness of a glacier surface: Implications for radar backscatter and aerodynamic roughness modelling. J. Glaciol., 52, 214-222, https:// doi.org/10.3189/172756506781828665.

Rivas, M. B., J. Maslanik, J. G. Sonntag, and P. Axelrad, 2006: Sea ice roughness from airborne lidar profiles. IEEE Trans. Geosci. Remote Sens., 44, 3032-3037, https://doi.org/10.1109/ TGRS.2006.875775.

Rosenblatt, M., 1956: Remarks on some nonparametric estimates of a density function. Ann. Math. Stat., 27, 832-837, https://doi.org/10.1214/aoms/1177728190.

Schenkman, A. D., M. Xue, and A. Shapiro, 2012: Tornadogenesis in a simulated mesovortex within a mesoscale convective system. J. Atmos. Sci., 69, 3372-3390, https://doi.org/10.1175/ JAS-D-12-038.1.

Simpson, J. J., and J. R. Stitt, 1998: A procedure for the detection and removal of cloud shadow from AVHRR data over land. IEEE Trans. Geosci. Remote Sens., 36, 880-897, https://doi.org/ 10.1109/36.673680.

Simpson, M. D., M. F. Jasinski, J. Borak, S. Blonski, J. Spruce, H. Walker, and L. Delle Monache, 2012: Integrating NASA earth science capabilities into the Interagency Modeling and Atmospheric Assessment Center for improvements in atmospheric transport and dispersion modeling. Lawrence Livermore National Laboratory, LLNL-TR-596732, 56 pp., https:// e-reports-ext.1lnl.gov/pdf/683472.pdf.

Strahler, A., D. Muchoney, J. Borak, M. Friedl, S. Gopal, E. Lambin, and A. Moody, 1999: Modis land cover product: Algorithm theoretical basis document version 5.0. NASA Algorithm Theoretical Basis Doc., 73 pp.

Stull, R. B., 1988: An Introduction to Boundary Layer Meteorology. Kluwer Academic, 666 pp.

University of Alabama in Huntsville, 2004: ARMOR dual-polarimetric Doppler radar paving the way for scientific advancement. NSSTC, http://www.nsstc.uah.edu/armor/about.php.

USGS, 2006: Landsat 4-5 Thematic Mapper (TM) level-2 data products-Surface reflectance. U.S. Geological Survey, accessed 1 March 2015, https://lta.cr.usgs.gov/L45TMLevel2SR.

—_ 2011: Landsat 7 Enhanced Thematic Mapper Plus (ETM+) level-2 data products—Surface reflectance. U.S. Geological Survey, accessed 1 March 2015, at https://lta.cr.usgs.gov/ L7ETMLevel2SR.

_ 2019a: Landsat 4-7 surface reflectance code LEDAPS product guide. U.S. Geological Survey, 38 pp., https://www.usgs.gov/media/files/landsat-4-7-surface-reflectance-code-ledapsproduct-guide.

— 2019b: Landsat 8 surface reflectance code LaSRC product guide. U.S. Geological Survey, 40 pp., https://www.usgs.gov/media/files/landsat-8-surface-reflectance-code-lasrc-productguide.

Vermote, E. F., D. Tanre, J. L. Deuze, M. Herman, and J.-J. Morcette, 1997: Second simulation of the satellite signal in the solar spectrum, 6s: An overview. IEEE Trans. Geosci. Remote Sens., 35, 675-686, https://doi.org/10.1109/36.581987.

Vickery, P. J., P. F. Skerlj, J. Lin, L. A. Twisdale Jr., M. A. Young, and F. M. Lavelle, 2006: HAZUS-MH hurricane model methodology. II: Damage and loss estimation. Nat. Hazards Rev., 7, 94-103, https://doi.org/10.1061/(ASCE)1527-6988(2006)7:2(94). 


\section{Earth Interactions - Volume 23 (2019) • Paper No. 5 • Page 28}

Wang, J., S. Cao, W. Pang, and J. Cao, 2017: Experimental study on effects of ground roughness on flow characteristics of tornado-like vortices. Bound.-Layer Meteor., 162, 319-339, https:// doi.org/10.1007/s10546-016-0201-6.

Wickham, J. D., S. V. Stehman, L. Gass, J. Dewitz, J. A. Fry, and T. G. Wade, 2013: Accuracy assessment of NLCD 2006 land cover and impervious surface. Remote Sens. Environ., 130, 294-304, https://doi.org/10.1016/j.rse.2012.12.001.

Wu, B., Q. Xing, N. Yan, W. Zhu, and Q. Zhuang, 2015: A linear relationship between temporal multiband MODIS BRDF and aerodynamic roughness in HiWATER wind gradient data. IEEE Geosci. Remote Sens. Lett., 12, 507-511, https://doi.org/10.1109/LGRS.2014.2348074.

Zeng, X., R. E. Dickinson, A. Walker, M. Shaikh, R. S. DeFries, and J. Qi, 2000: Derivation and evaluation of global $1-\mathrm{km}$ fractional vegetation cover data for land modeling. J. Appl. Meteor, 39, 826-839, https://doi.org/10.1175/1520-0450(2000)039<0826:DAEOGK >2.0.CO;2.

Zhang, R. H., C. Y. Zhu, X. M. Sun, and Z. L. Zhu, 2004: The estimation of distribution in field scale of surface aerodynamic roughness using remote sensing data. Proc. IEEE Int. Conf. on Geoscience and Remote Sensing Symp. 2004, Anchorage, AK, Institute of Electrical and Electronics Engineers, Vol. 7, 4666-4669, https://doi.org/10.1109/IGARSS.2004.1370198.

Zheng, D., R. Van Der Velde, Z. Su, M. J. Booij, A. Y. Hoekstra, and J. Wen, 2014: Assessment of roughness length schemes implemented within the Noah land surface model for high-altitude regions. J. Hydrometeor., 15, 921-937, https://doi.org/10.1175/JHM-D-13-0102.1.

Zhu, Z., and C. E. Woodcock, 2012: Object-based cloud and cloud shadow detection in Landsat imagery. Remote Sens. Environ., 118, 83-94, https://doi.org/10.1016/j.rse.2011.10.028. 